\title{
Влияние электростатического поля периферии на вентильный фотоэффект в контактах металл-полупроводник с барьером Шоттки
}

\author{
(C) H.A. Торхов ${ }^{1,2,3}$ \\ ${ }^{1}$ АО „Научно-исследовательский институт полупроводниковых приборов“, \\ 634034 Томск, Россия \\ 2 Томский университет систем управления и радиоэлектроники, \\ 634050 Томск, Россия \\ ${ }^{3}$ Научно-исследовательский Томский государственный университет, \\ 634050 Томск, Россия \\ E-mail: trkf@mail.ru
}

(Получена 20 апреля 2017 г. Принята к печати 4 декабря 2017 г.)

\begin{abstract}
Исследования электростатической системы плоских контактов металл-полупроводник с барьером Шоттки выявили нетривиальную зависимость их токовой и вольтовой фоточувствительностей (вентильного фотоэффекта) от формы контактов. Особенности использования вентильного фотоэффекта в таких контактах во многом определяются встроенным электростатическим полем периферии, модуль которого зависит от периметра и площади контактов. Таким образом, повышение эффективности преобразования контактами Шоттки световой энергии в электрическую требует использования методов оптимизации, в основе которых лежат изложенные в данной работе положения физической модели электростатической системы плоских контактов Шоттки с учетом электростатических полей периферии. Эффект „резонанса горячих электронов“, приводящий к увеличению внешней квантовой эффективности фотодиодов с барьером Шоттки, может быть объяснен усилением полевой эмиссии электронов электростатическим полем периферии.
\end{abstract}

DOI: $10.21883 /$ FTP.2018.10.46455.8620

\section{1. Введение}

Благодаря вентильному или фотогальваническому фотоэффекту $[1,2]$ плоские выпрямляющие контакты металл-полупроводник $(\mathrm{M}-\Pi)$ с барьером Шоттки (БШ) [3], для которых характерно наличие области пространственного (объемного) заряда (ОП3, Space Charge - SCh), способны преобразовывать световую энергию в электрическую. Несмотря на давнюю историю этого открытия, природа вентильного фотоэффекта в таких контактах все еще не нашла достаточно полного физического объяснения, а их свойства как фотоэлектрических преобразователей до сих пор недостаточно хорошо изучены. Так, например, эффект „резонанса горячих электронов“", приводящий к увеличению внешней квантовой эффективности фотодиодов с барьером Шоттки [4], в рамках теории Фаулера [5] до сих пор так и не получил достаточного физического объяснения [6,7]. Кроме этого, не поддается объяснению и тот факт, что в контактах М-П с БШ небольших размеров (диаметром $D<100$ мкм) обратные токи насыщения $I_{S, r}$ могут значительно (на несколько порядков) превышать прямые токи насыщения $I_{S, f}[8]$, а амплитуда фотоэлектродвижущей силы (фотоэдс) $U_{\mathrm{Ph}}$, как и сила фототока $I_{\mathrm{Ph}}$, нетривиальным образом зависит от геометрической формы контактов [9], что не может быть объяснено в рамках известных представлений о пропускной способности барьера Шоттки. В результате мы видим, что проводящая способность обратно смещенного барьера Шоттки по какой-то причине значительно превышает ожидаемую (предсказы- ваемую теоретически). Остается также открытым вопрос и о нетривиальном влиянии формы контактов Шоттки на их вольтовую $\beta_{U}$ и токовую $\beta_{I}$ фоточувствительности. Изучение этого вопроса позволит разработать методы повышения эффективности фотоэлектрических преобразователей на основе контактов металл-полупроводник с барьером Шоттки, а также оптимизировать режимы работы диодов Шоттки в миллиметровых и субмиллиметровых диапазонах длин электромагнитных волн.

В связи с этим в данной работе методом вольт-амперных характеристик (BAX) и методами атомно-силовой микроскопии (АСM) исследуются фотопреобразующие свойства контактов М-П с БШ на электронном арсениде галлия $(n-\mathrm{GaAs}(100))$ с целью повышения их вольтовой $\beta_{U}$ и токовой $\beta_{I}$ фоточувствительностей.

\section{2. Методика проведения экспериментов}

Выпрямляющие $\mathrm{Au} / n-n^{+}-\mathrm{GaAs}(100)$-контакты $\mathrm{M}-\Pi$ с БШ формировались по стандартному технологическому маршруту электрохимическим осаждением пленки золота $\mathrm{Au}$ толщиной 0.5 мкм на поверхность $n$-GaAs в окна фоторезиста с последующим его удалением. Толщина эпитаксиального слоя $n$-GaAs с концентрацией $N_{D}=6.4 \cdot 10^{14} \mathrm{~cm}^{-3}$ составляла 1 мкм. Со стороны $n^{+}$-подложки $\left(N_{D}=2 \cdot 10^{18} \mathrm{~cm}^{-3}\right)$ электрохимическим осаждением с использованием стандартных технологических операций был сформирован омический контакт на основе $\mathrm{AuGeNi}+\mathrm{Au}$. 
В работе исследовались четыре геометрических формы Аu-контактов с БШ, соответствующие четырем геометрическим случаям $\xi=(I, K, L$ и $M)$ отношения длины их периметра $P_{\xi}$ к их площади $S_{\xi}$, характеризуемые параметром $\left.\xi_{\xi}=P_{\xi} / S_{\xi}: 1\right)$ круглые контакты $I$-типа диаметром $D_{I}$, для которых $\left.\xi_{I}=4 / D_{I} ; 2\right)$ контакты $K$-типа с постоянной площадью $S_{K}=$ const и меняющимся периметром $\left.P_{K}, \xi_{K}=\xi\left(P_{K}\right) ; 3\right)$ контакты $L$-типа, для которых периметр $P_{L}=$ const постоянен, а $S_{L}-$ меняющийся параметр $\xi_{L}=\xi\left(S_{L}\right)$ и 4) контакты $M$-типа, для которых значение параметра $\xi_{M}=P_{M} / S_{M}=$ const постоянно, а $P_{M}$ и $S_{M}$ - изменяющиеся параметры $\xi_{M}=\xi\left(P_{M}, S_{M}\right)$.

Контакты $I$-типа $(I=1,2,3,-, i,-, 7)$ были выполнены в виде круглых дисков диаметрами $D_{I}: D_{I 1}=500$ мкм, $D_{I 2}=200$ мкм, $D_{I 3}=100$ мкм, $D_{I 4}=50$ мкм, $D_{I 5}=30$ мкм, $D_{I 6}=15$ мкм и $D_{I 7}=5$ мкм (рис. 1$)$. Для таких контактов, как указывалось выше, отношение их периметра к площади $\xi_{I}=4 / D$.

Контакты $K$-типа $(K=1,2,-, k,-, 6)$ имели одинаковую площадь $S_{K}=\mathrm{const} \approx 7853.98$ мкм $^{2}$, соответствующую площади $S_{K 1}$ круглого контакта диаметром $D_{K 1}=100$ мкм, но разный периметр $P_{K}: P_{K 1}=314.16$ мкм (круг $\quad D_{K 1}=100$ мкм), $\quad P_{K 2}=354.49$ мкм $\quad$ (квадрат $88.62 \times 88.62$ мкм), $P_{K 3}=472.70$ мкм (прямоугольник $40 \times 196.35$ мкм),$\quad P_{K 4}=825.40$ мкм $\quad$ (прямоугольник $20 \times 392.70$ мкм),$\quad P_{K 5}=1590.80$ мкм $\quad$ (прямоугольник $10 \times 785.4$ мкм) и $P_{K 6}=3151.60$ мкм (прямоугольник $5 \times 1570.8$ мкм) (рис. 2).

Контакты $L$-типа $(L=1,2,-, l,-, 7)$ имели одинаковую длину периметра $P_{L}=\mathrm{const}=600$ мкм, но разную площадь $S_{L}: S_{L 1}=28648$ мкм $^{2} \quad$ (круг $D_{L 1}=190.99$ мкм), $S_{L 2}=10400$ мкм $^{2}$ (прямоугольник $40 \times 260$ мкм), $S_{L 3}=$ $=5600$ мкм $^{2} \quad$ (прямоугольник $20 \times 280$ мкм $), \quad S_{L 4}=$ $=2900$ мкм $^{2} \quad$ (прямоугольник $10 \times 290$ мкм $), \quad S_{L 5}=$ $=1475$ мкм $^{2}$ (прямоугольник $5 \times 295$ мкм), $S_{L 6}=891$ мкм $^{2}$ (прямоугольник $3 \times 297$ мкм) и $S_{L 7}=596$ мкм $^{2}$ (прямоугольник $2 \times 298$ мкм) (рис. 3$)$.

Контакты $M$-типа $(M=1,2,-, m,-, 7) \quad$ имели одинаковую ширину $A=\mathrm{const}=20$ мкм, но разную длину $b_{M}: b_{M 1}=20$ мкм, $b_{M 2}=40$ мкм, $b_{M 3}=80$ мкм, $b_{M 4}=160$ мкм,$\quad b_{M 5}=320$ мкм,$\quad b_{M 6}=640$ мкм и $b_{M 7}=1280$ мкм (рис. 4). Прямоугольная форма этих контактов была выполнена таким образом, что отношение периметра $P_{M}$ к площади $S_{M}$ с точностью до $a$ было постоянным $\xi_{M} \approx$ const. Понятно, что чем меньше ширина $a \ll b_{M}$, тем с большей точностью будет выполняться это соотношение.

Измерение аддитивных приборных характеристик: прямых $I_{f}\left(U_{f}\right)(f-$ для прямой ветви) и обратных $I_{r}\left(U_{r}\right)(r$ - для обратной ветви) темновых „Dark“ и световых „Light“ статических вольт-амперных характеристик (BАX) контактов $I-, K$-, $L$ - и $M$--типов, а также их емкостей $C_{\xi}$ происходило четырехзондовым методом Кельвина с использованием измерительной системы B1500A производства „Agilent Technologies“. Разрешение B1500A по напряжению (0.5 мкВ), по току (10 фА) и по емкости (0.1 фФ) обеспечивало достаточную точность проводимых оценок значений фотоэдс $U_{\mathrm{Ph}}^{\xi}$ и фототока $I_{\mathrm{Ph}}^{\xi}$ исследуемых контактов. Освещение контактов осуществлялось белым светом постоянной мощности.

Модули значений прямых $I_{S, f}^{\xi}$ и обратных $I_{S, r}^{\xi}$ токов насыщения находились графическим методом по пересечению с осью ординат линейных аппроксимаций построенных в полулогарифмическом масштабе линейных зависимостей $\ln \left(I_{S, f(r)}^{\xi}\right)$ от $U_{f(r)}$.

Для определения эффективной (измеряемой) высоты барьера Шоттки $\varphi_{b m, f(r)}^{\xi}$ контактов $K-, M-, L$ - и $I$-типов методом ВАХ использовалось выражение [10]:

$$
\varphi_{b m, f(r)}^{\xi}=\frac{k T}{q} \ln \left(\frac{R^{*} T^{2}}{J_{S, f(r)}^{\xi}}\right), \quad R^{*}=\frac{4 \pi q m^{*} k^{2}}{\hbar^{3}},
$$

где $R^{*}-$ эффективная постоянная Ричардсона, $J_{S, f(r)}^{\xi} \equiv J_{S, f(r), \text { Dark }}^{\xi}=\frac{I_{S, f(r), \text { Dark }}^{\xi}}{S_{\xi}}-$ плотность темнового (Dark) тока насыщения $\left(\left[J_{S, f(r)}^{\xi}\right]=\mathrm{A} \cdot \mathrm{cm}^{-2}\right), T-$ температура, $k-$ постоянная Больцмана, $\hbar-$ постоянная Планка, $q$ - электрический заряд электрона.

Значение показателя идеальности $n_{\xi}$ определялось в интервале токов $10^{-7}-10^{-4} \mathrm{~A}$ по наклону линейного участка записанной в полулогарифмическом масштабе прямой ВАХ из выражения [10]

$$
n_{\xi}=\frac{q}{k T} \frac{\partial U}{\partial\left(\ln \left(I_{f}^{\xi}\right)\right)} .
$$

Освещение включенного в замкнутую электрическую цепь контакта Шоттки как при отсутствии, так и при наличии внешнего смещения $U_{f(r)}$ приводило к возникновению фотоэдс $U_{\mathrm{Ph}}^{\xi}$ и появлению в цепи фототока $I_{\mathrm{Ph}}^{\xi}$. Будем полагать, что результирующий электрический ток $I_{r \text { Light }}^{\xi}\left(U_{r}\right)$ в такой цепи при наличии освещения в общем случае будет определяться суммой темнового тока $I_{r(f) \text {, Dark }}^{\xi}\left(U_{r(f)}\right) \equiv I_{r(f)}^{\xi}\left(U_{r(f)}\right)$ и тока фотоэдс $I_{\mathrm{Ph}}^{\xi}=I_{\mathrm{Ph}}^{\xi}\left(U_{\mathrm{Ph}}^{\xi}\right)$ и в общем случае может быть записан как

$$
I_{r(f), \text { Light }}^{\xi}\left(U_{r(f)}\right)=I_{r(f), \text { Dark }}^{\xi}\left(U_{r(f)}\right)+I_{\mathrm{Ph}}^{\xi}(W) .
$$

Отсюда видно, что фототок $I_{\mathrm{Ph}}^{\xi}$ при заданном обратном смещении может быть определен по разности световых $I_{r \text {,Light }}^{\xi}\left(U_{r}\right)$ и темновых $I_{r, \text { Dark }}^{\xi}\left(U_{r}\right)$ обратных токов [9].

Вольтовая $\beta_{U}^{\xi}$ и токовая $\beta_{I}^{\xi}$ фоточувствительности исследуемых контактов М-П с БШ находились из параметров их статических прямых $I_{f, \text { Light }}^{\xi}\left(U_{f}\right)$ и обратных $I_{r, \text { Light }}^{\xi}\left(U_{r}\right)$ световых ВАХ с использованием выражений (4)

$$
\beta_{U}^{\xi}=\frac{U_{\mathrm{Ph}}^{\xi}}{W}, \quad \beta_{I}^{\xi}=\frac{I_{\mathrm{Ph}}^{\xi}}{W},
$$

где $[W]=\mathrm{B}$ - падающая на диод (под диодом здесь будем понимать контакт М-П с БШ) мощность. 


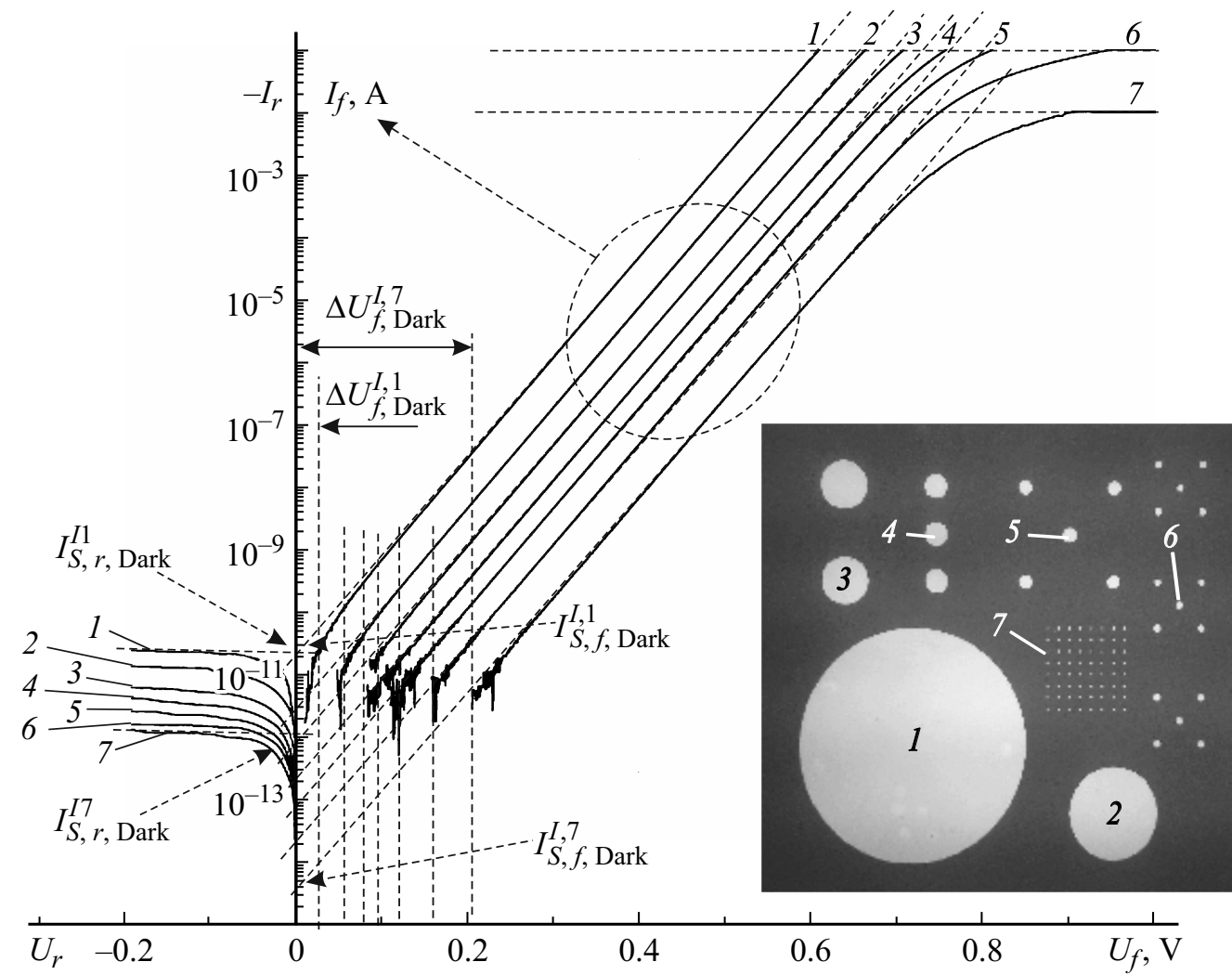

$a$

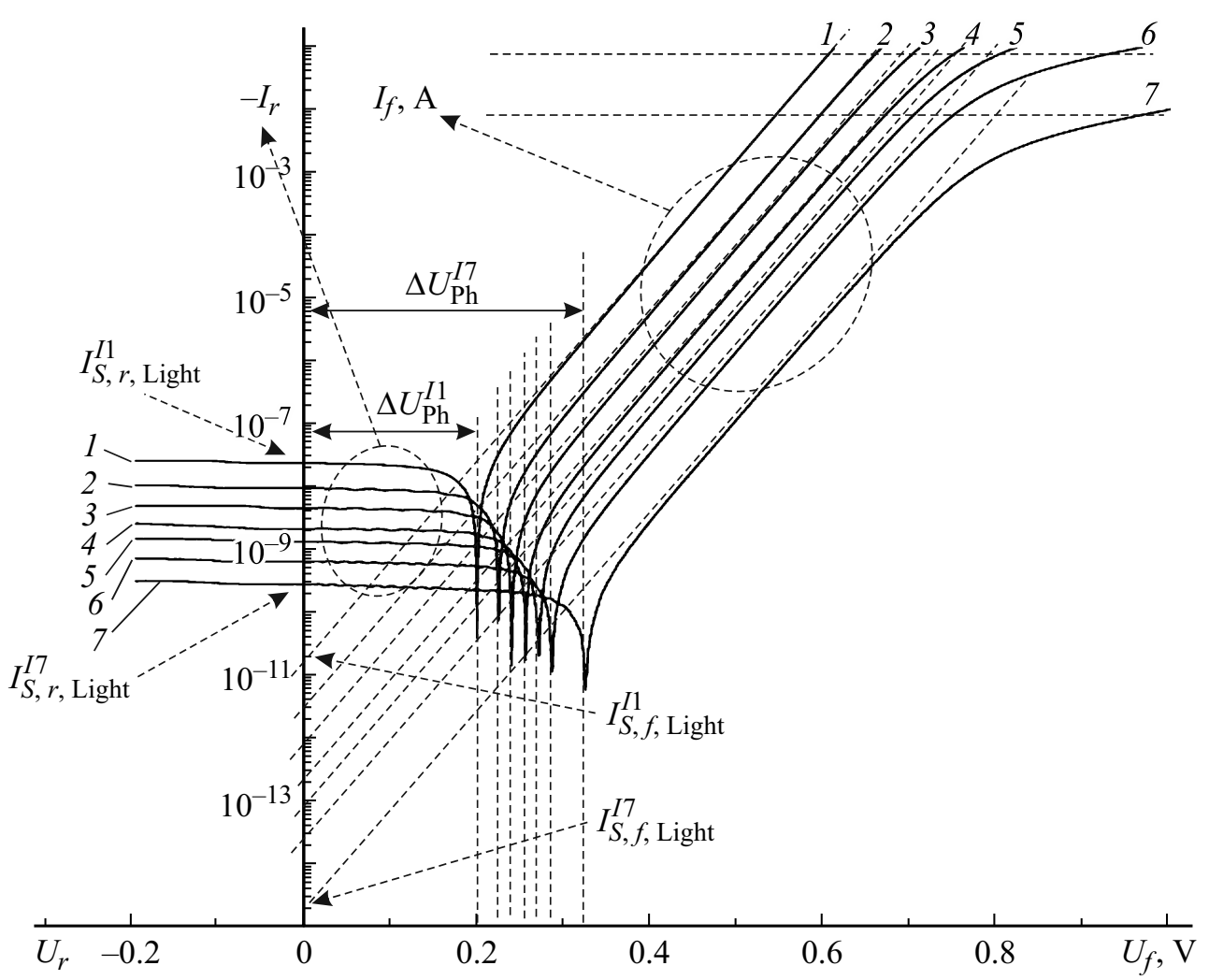

$b$

Рис. 1. Прямые $I_{f}^{I}\left(U_{f}\right)$ и обратные $I_{r}^{I}\left(U_{r}\right)$ ВАХ контактов $I$-типа: $1-D_{I 1}=500$ мкм, $2-D_{I 2}=200$ мкм, $3-D_{I 3}=100$ мкм, $4-D_{I 4}=50$ мкм, $5-D_{I 5}=30$ мкм, $6-D_{I 6}=15$ мкм и $7-D_{I 7}=5$ мкм - без освещения (на вставке представлено оптическое изображение чипа контактов $I$-типа) ( $a$ ) и при наличии освещения $(b)$. 


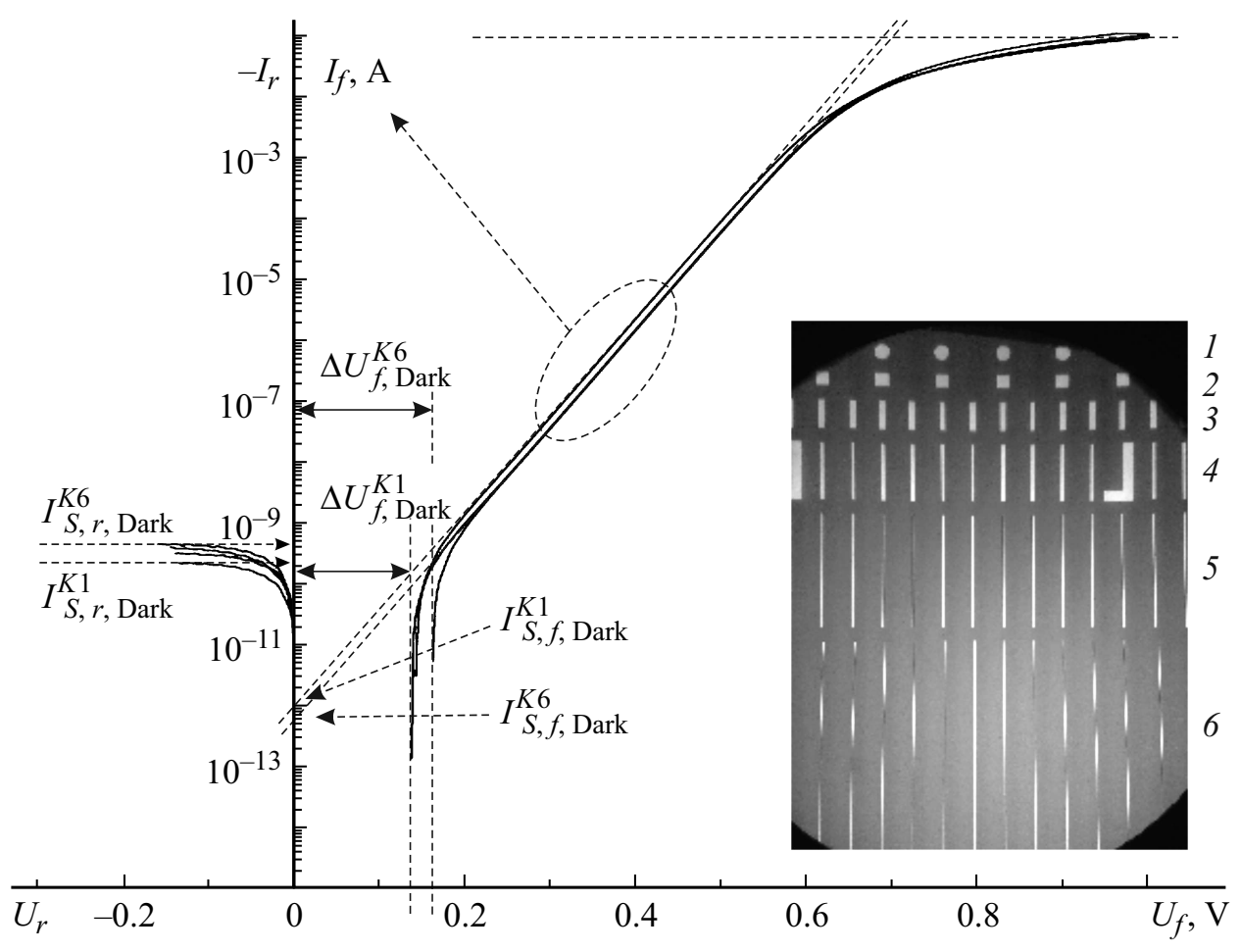

$a$

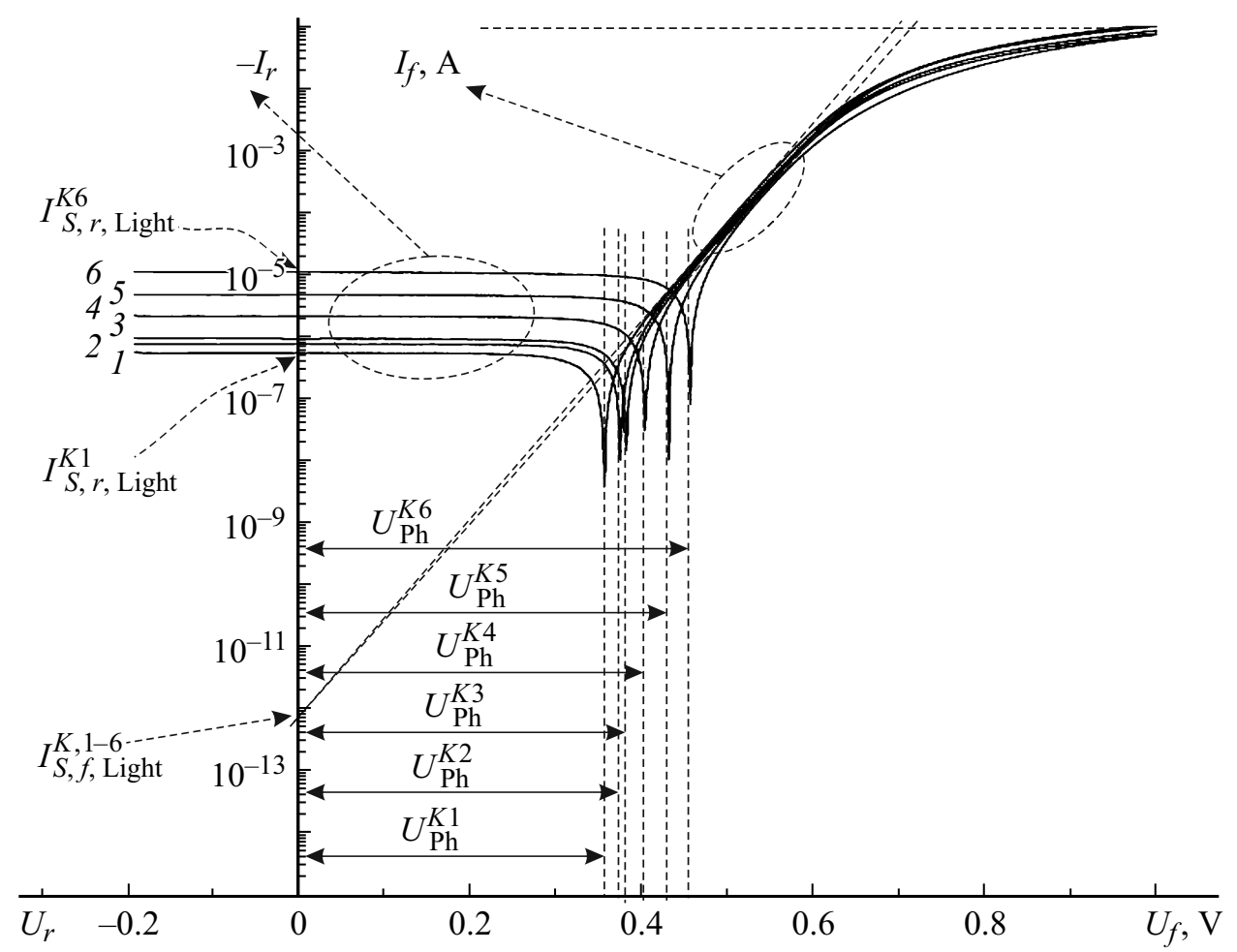

$b$

Рис. 2. Прямые $I_{f}^{K}\left(U_{f}\right)$ и обратные $I_{r}^{K}\left(U_{r}\right)$ ВАХ контактов $K$-типа: $1-P_{K 1}=314.16$ мкм (круг $D_{K 1}=100$ мкм), $2-P_{K 2}=354.49$ мкм (квадрат), $3-P_{K 3}=472.70$ мкм (прямоугольник), $4-P_{K 4}=825.40$ мкм, $5-P_{K 5}=1590.80$ мкм и $6-P_{K 6}=3151.60$ мкм - без освещения (на вставке представлено оптическое изображение чипа контактов $K$-типа) $(a)$ и при наличии освещения $(b)$. 


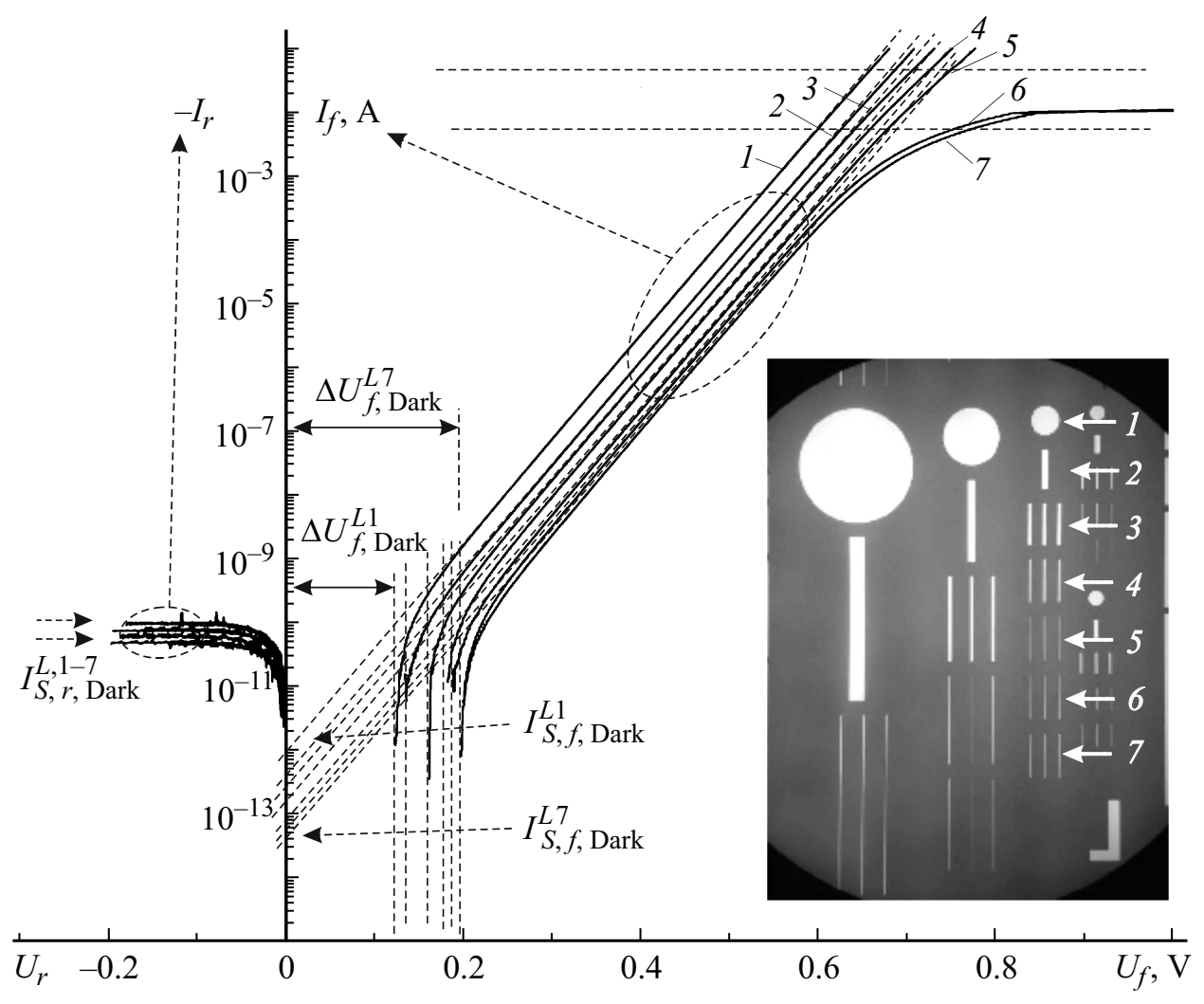

a

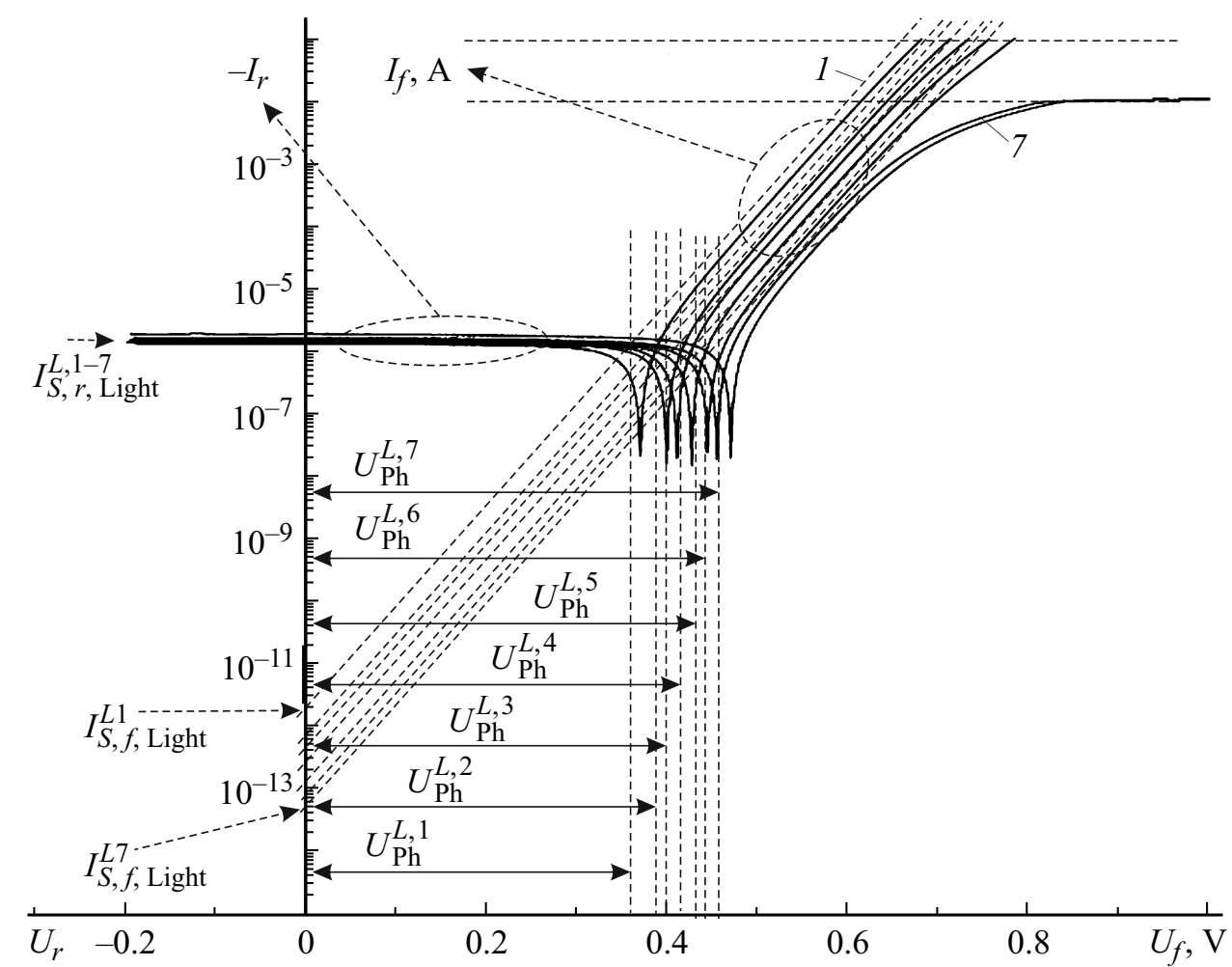

Рис. 3. Прямые $I_{f}^{L}\left(U_{f}\right)$ и обратные $I_{r}^{L}\left(U_{r}\right)$ ВАХ контактов $L$-типа: $1-S_{L 1}=28648$ мкм $^{2}$ (круг $D_{L 1}=190.99$ мкм), $2-S_{L 2}=10400$ мкм $^{2}$ (прямоугольник $40 \times 260$ мкм), $3-S_{L 3}=5600$ мкм $^{2}, 4-S_{L 4}=2900$ мкм $^{2}, 5-S_{L 5}=1475$ мкм $^{2}$, $6-S_{L 6}=891$ мкм $^{2}$ и $7-S_{L 7}=596$ мкм $^{2}-$ без освещения (на вставке представлено оптическое изображение чипа контактов $L$-типа) (a) и при наличии освещения $(b)$. 


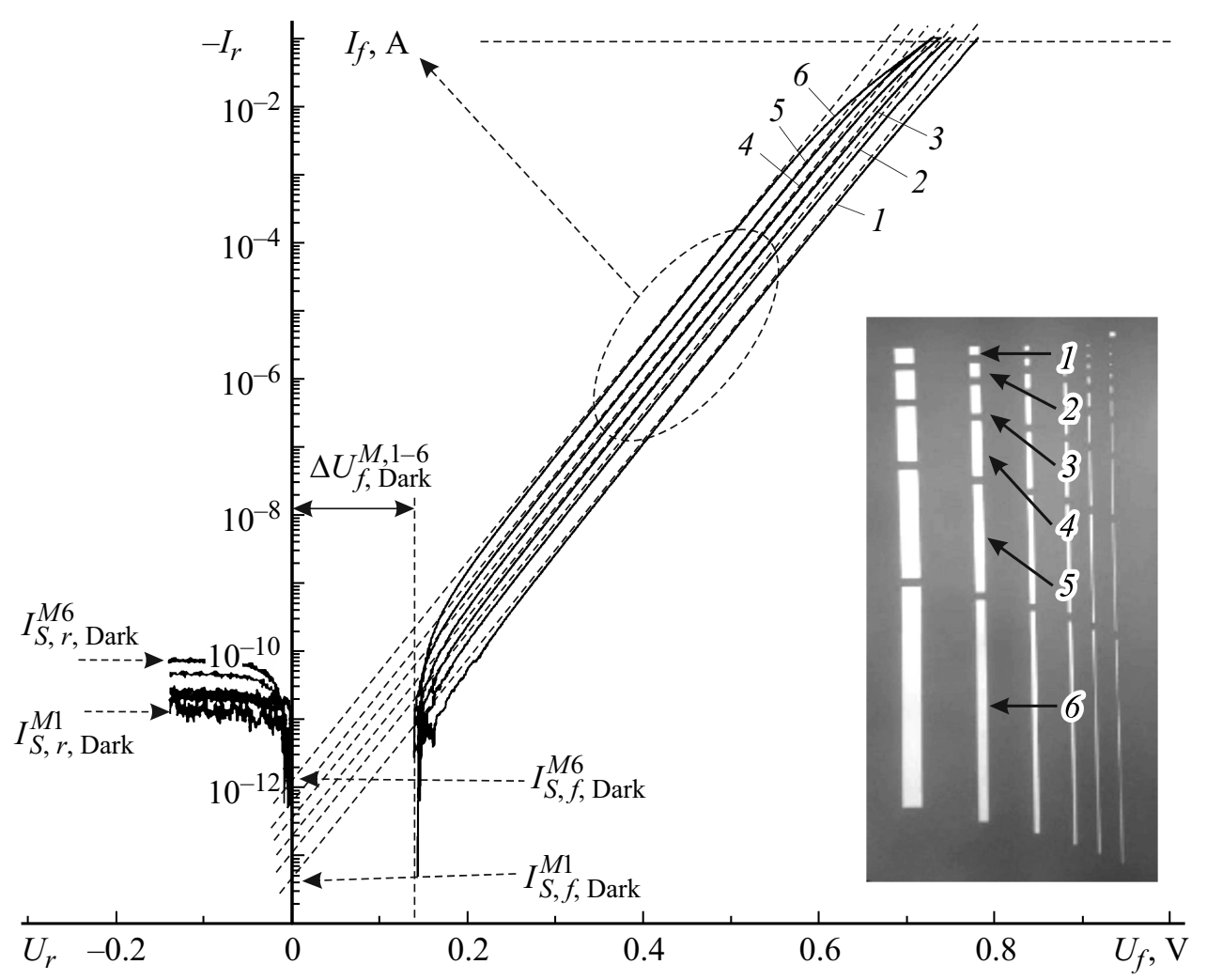

$a$

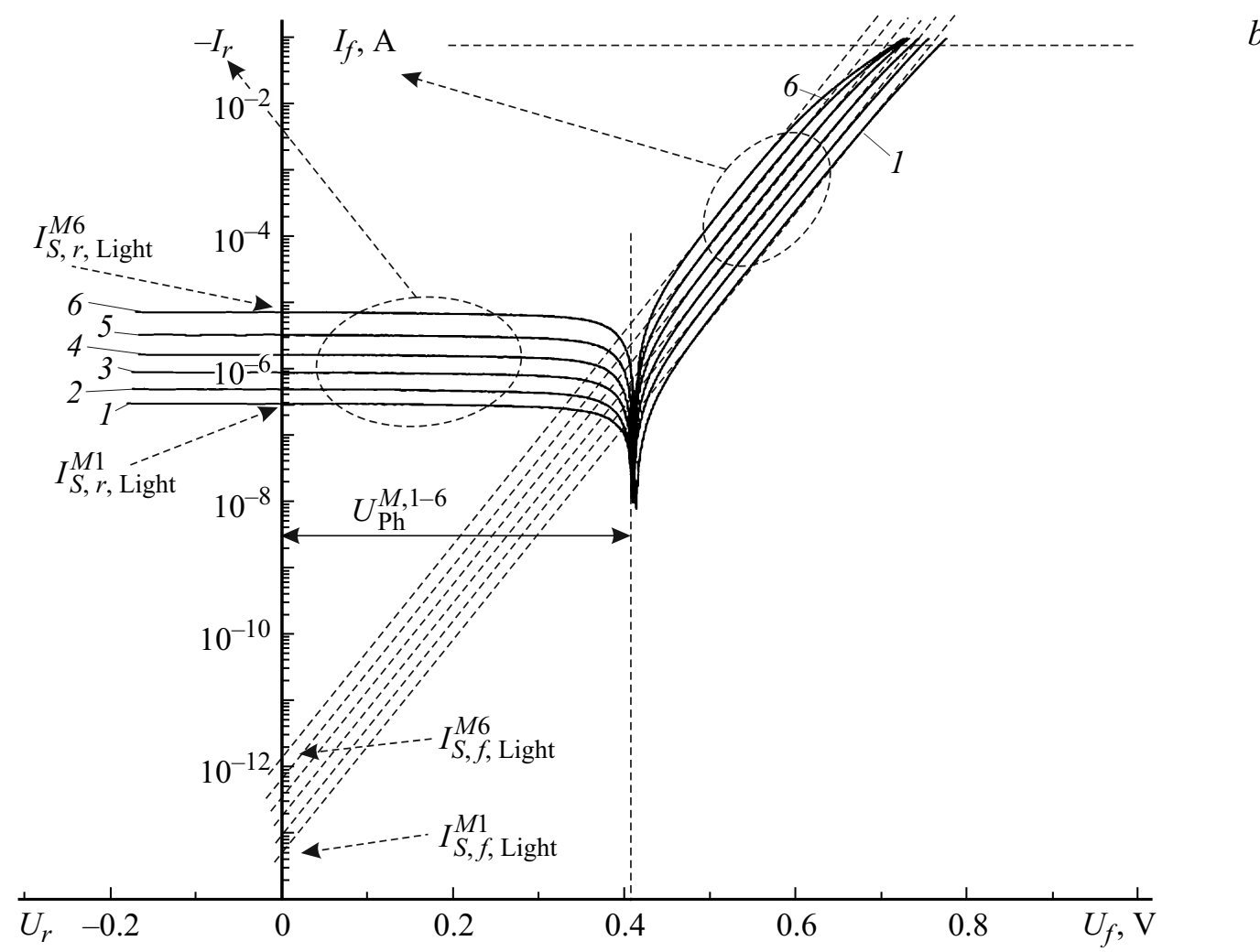

Рис. 4. Прямые $I_{f}^{M}\left(U_{f}\right)$ и обратные $I_{r}^{M}\left(U_{r}\right)$ ВАХ контактов $M$-типа при $a=20$ мкм: $1-b_{M 1}=20$ мкм, $2-b_{M 2}=40$ мкм, $3-b_{M 3}=80$ мкм, $4-b_{M 4}=160$ мкм, $5-b_{M 5}=320$ мкм, $6-b_{M 6}=640$ мкм и $7-b_{M 7}=1280$ мкм - без освещения (на вставке представлено оптическое изображение чипа контактов $M$-типа) $(a)$ и при наличии освещения $(b)$. 

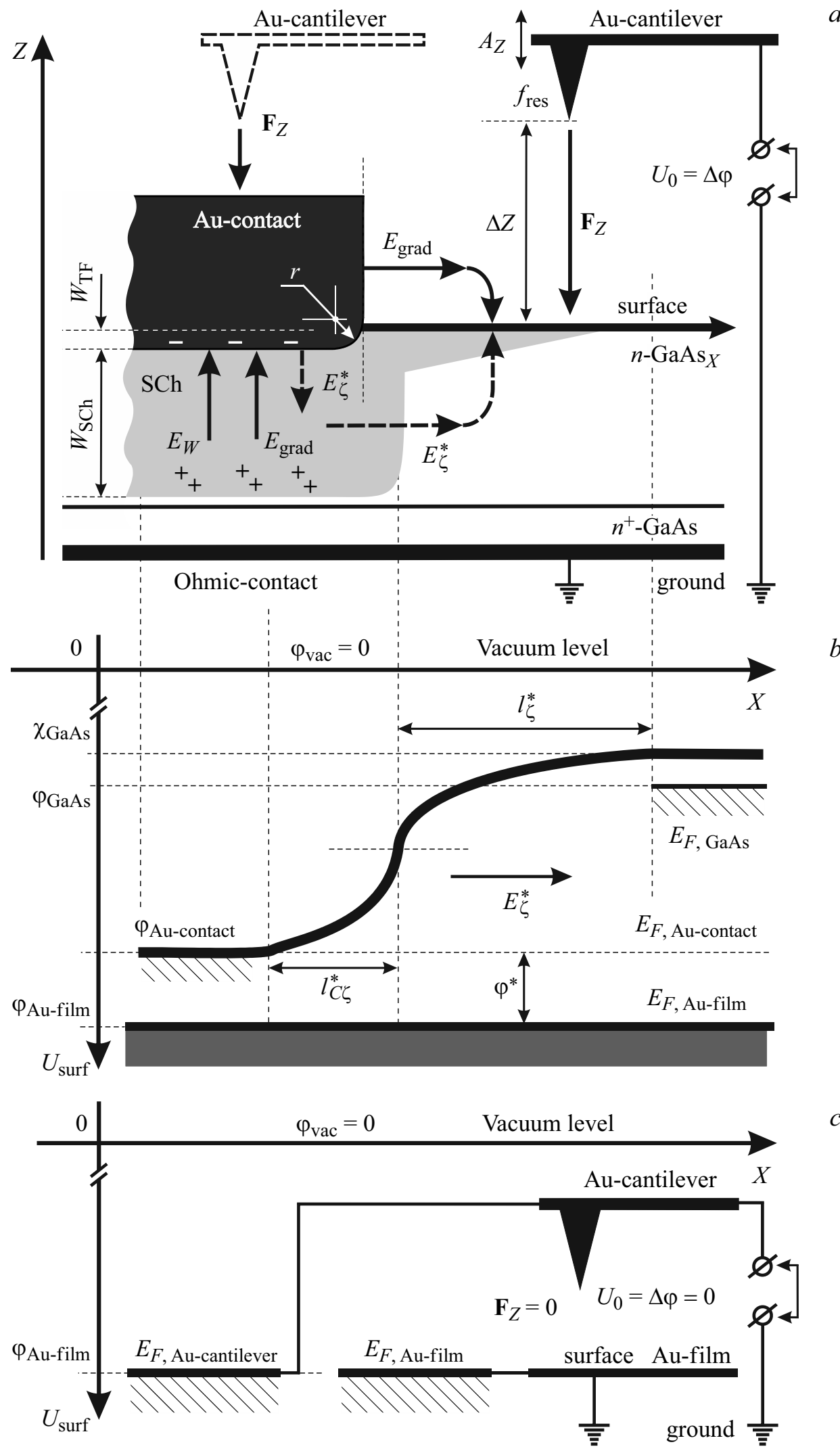

Рис. 5. Схематические изображения способа измерения методом Кельвина АСМ поверхностного электростатического потенциала контакта металл-полупроводник с барьером Шоттки $(a)$, его энергетической диаграммы $(b)$ и способа измерения методом Кельвина АСМ поверхностного электростатического потенциала пленки золота $(c)$. 
Результирующая фотоэдс $U_{\mathrm{Ph}}^{\xi}$ определялась по границе „мертвой“ области $\Delta U_{f, \text { Light }}^{\xi}\left(U_{\mathrm{Ph}}^{\xi}=\Delta U_{f, \text { Light }}^{\xi}\right)$, проявляющейся на начальных участках прямых световых ВАХ в виде отсутствия прямых токов [9].

Сложность возникает при определении абсолютных значений $\beta_{U}^{\xi}$ и $\beta_{I}^{\xi}$. Если значения $U_{\mathrm{Ph}}^{\xi}$ и $I_{\mathrm{Ph}}^{\xi}$ могут быть легко найдены из световых ВАX с достаточной точностью, то измерение поглощенной контактом световой мощности $W$ представляет собой более сложную задачу. Так как эффективность преобразования световой энергии в электрическую подразумевает относительные изменения характеристик контакта, проще рассматривать не абсолютные, а относительные значения $\tilde{\beta}_{U}^{\xi}$ и $\tilde{\beta}_{I}^{\xi}$. Для этого нормируем значения $\beta_{U}^{\xi}$ и $\beta_{I}^{\xi}$ по максимальным значениям $\beta_{U}^{L 7}$ и $\beta_{I}^{K 7}$. Забегая вперед, отметим, что $\beta_{U}^{L 7}$ и $\beta_{I}^{K 7}$ в данном эксперименте имеют максимальные значения:

$$
\tilde{\beta}_{U}^{\xi}=\frac{\beta_{U}^{\zeta}}{\beta_{U}^{L 7}} \approx \frac{U_{\xi}^{\mathrm{Ph}}}{U_{L 7}^{\mathrm{Ph}}} \quad \text { и } \quad \tilde{\beta}_{I}^{\xi}=\frac{\beta_{I}^{\xi}}{\beta_{I}^{K 7}} \approx \frac{I_{\xi}^{\mathrm{Ph}}}{I_{K 7}^{\mathrm{Ph}}} .
$$

Из (5) видно, что для определения значений относительных величин $\tilde{\beta}_{U}^{\xi}$ и $\tilde{\beta}_{I}^{\xi}$ уже не надо определять падающую на диод мощность оптического излучения $W$. В этом случае получается, что максимальное относительное значение вольтовой фоточувствительности будет у контактов $L$-типа $\tilde{\beta}_{U}^{L 7}=1$, а максимальное относительное значение токовой фоточувствительности будет у контактов $K$-типа $\tilde{\beta}_{I}^{K 7}=1$. Таким образом, относительные величины $\tilde{\beta}_{U}^{\xi}$ и $\tilde{\beta}_{I}^{\zeta}$ показывают, насколько токовая и вольтовая фоточувствительности контактов исследуемых типов отличаются от максимально возможных для данного эксперимента значений.

Двухпроходная методика АCM-измерения аддитивных электрофизических параметров: пространственного $h(x, y)$ и потенциального $\Delta \varphi(x, y)$ („Kelvin probe“ - АCМ-метод Кельвина) поверхностных рельефов арсенид-галлиевых $(\mathrm{GaAs})$ и золотых $(\mathrm{Au})$ контактов с использованием атомно-силового микроскопа (ACM) „Solver-HV“ в полуконтактном режиме на воздухе при нормальных условиях была подробно описана в работах $[11,12]$ и аналогична методике, описанной в [13]. Согласно [14], в режиме метода Кельвина измеряется контактная разность потенциалов (КРП), равная разности между поверхностным потенциалом иглы кантилевера $\varphi_{p}(p-$ probe $)$ и потенциалом $\varphi_{S(m)}$ исследуемого участка поверхности $(s-$ semiconductor, в данном случае $\varphi_{\mathrm{GaAs}}$, или металла $m-$ metal, в данном случае $\left.\varphi_{\mathrm{Au}}\right)$ на определенном расстоянии от поверхности $\Delta Z$ порядка десятков нанометров (рис. $5, a$ ):

$$
\text { КРП } \equiv \Delta \varphi(x, y)=\varphi_{p}-\varphi_{S(m)}(x, y) .
$$

Отсюда легко находится потенциал (работа выхода $\left.A=q \varphi_{S(m)}\right)$ исследуемого участка поверхности как $\varphi_{S(m)}(x, y)=\varphi_{p}-\Delta \varphi(x, y)$.
Сила электростатического взаимодействия иглы кантилевера (зонда) с исследуемой поверхностью направлена по нормали (ось „Z“) к поверхности в исследуемой точке и определяется градиентом энергии $E=C U^{2} / 2$ запасенной емкостью $C$ системы зонд-поверхность [14]:

$$
F_{z, i}=-\frac{\partial E}{\partial z}=-\frac{1}{2} U_{i}^{2} \frac{\partial C}{\partial Z},
$$

где $U_{i}$ - разность потенциалов между кантилевером и $i$-й точкой поверхности, включающей КРП, внешний переменный сигнал с амплитудой $U_{1}=0.5 \mathrm{~B}$ и по частоте совпадающей с резонансной частотой собственных механических колебаний балки кантилевера $f_{\text {res }}=400$ КГц, а также постоянное компенсирующее напряжение $U_{0}$ :

$$
U_{i}=U_{0}-\Delta \varphi_{i}(x, y)+U_{1} \sin \left(f_{\text {res }} t\right) .
$$

Подставляя (8) в (7), получим

$$
F_{z}\left(f_{\text {res }}\right)=-\frac{1}{2}\left\{\left[U_{0}-\Delta \varphi(x y)\right] U_{1} \sin \left(f_{\text {res }} t\right)\right\} \frac{\partial C}{\partial z} .
$$

Из условия баланса $F_{z}\left(f_{\text {res }}\right)=0$ и определяется значение контактной разности потенциалов, равное значению внешнего компенсирующего напряжения $\Delta \varphi=U_{0}$ (рис. $5, a$ ).

Оценка минимального частотного предела быстродействия исследуемых контактов Шоттки с максимальной площадью $S_{I}$ для $D_{I}=500$ мкм составила $f_{T}=1 /\left(2 \pi R_{S} C_{\xi}\right)>600$ ГЦ $\quad\left(C_{\text {Dark }}^{I}=159\right.$ пФ, $R_{S, \text { Dark }}^{I}=0.003$ Ом, табл. 1), что значительно превышает частоту собственных резонансных механических колебаний кантилевера $f_{\text {res }}=400$ КГц. Из этого следует, что электростатическая система контакта Шоттки менее чем за одну миллионную долю периода колебания кантилевера успевает прийти в состояние термодинамического равновесия за счет протекания через барьер Шоттки токов насыщения $10^{-12}<f_{S, r}^{\xi}<10^{-10} \mathrm{~A}$. Таким образом, измеряемые в работе значения КРП $\equiv \Delta \varphi_{i}(x, y)(6)$ обусловлены именно поверхностным электростатическим потенциалом иглы кантилевера и электростатическим потенциалом исследуемой поверхности без влияния падения напряжения на областях пространственных зарядов, сформированных под барьером Шоттки и в приповерхностной области полупроводника за счет искривления зон.

Для проведения АСМ-измерений использовались проводящие Si-кантилеверы с золотым покрытием и работой выхода, равной работе выхода золотой пленки $q \varphi_{p}=q \varphi_{\mathrm{Au} \text {-film }} \approx 5.2$ эВ ( $q=1$ в СГСЭ). Таким образом, измеряемое в экспериментах значение КРП сплошной пленки золота толщиной 0.5 мкм, согласно (6), составило $\Delta \varphi_{\mathrm{Au}} \approx 0.00$ эВ. Погрешность измерения КРП поверхности (так называемое „приборное влияние“ $[15,16])$ не превышала $25 \%$ в непосредственной близости от измеряемого контакта и $2.5 \%$ на расстоянии 2 мкм от него. Число шагов по кадровой и строчной разверткам выбиралось равным 256. 
Таблица 1. Параметры световых („Light“) и темновых („Dark“) BAX контактов I-типа

\begin{tabular}{|c|c|c|c|c|c|c|c|}
\hline$i$ & 7 & 6 & 5 & 4 & 3 & 2 & 1 \\
\hline Диаметр $D_{I}$, мкм & 5 & 15 & 30 & 50 & 100 & 200 & 500 \\
\hline$\varphi_{b m, f, \text { Dark }}^{I}$, эB & 0.871 & 0.887 & 0.891 & 0.894 & 0.894 & 0.894 & 0.894 \\
\hline$\varphi_{b m, f, \text { Light }}^{I},{ }^{\prime}, \mathrm{B}$ & 0.907 & 0.910 & 0.905 & 0.907 & 0.903 & 0.912 & 0.918 \\
\hline$\varphi_{b m, r, \text { Dark }}^{I},{ }^{\prime}$ ЭB & 0.721 & 0.760 & 0.750 & 0.804 & 0.837 & 0.870 & 0.890 \\
\hline$\varphi_{b m, r, \text { Light }}^{I}$, эB & 0.592 & 0.626 & 0.648 & 0.662 & 0.674 & 0.692 & 0.715 \\
\hline$n_{\text {Dark }}^{I}$ & 1.09 & 1.08 & 1.07 & 1.05 & 1.05 & 1.05 & 1.05 \\
\hline$n_{\text {Light }}^{I}$ & 1.11 & 1.10 & 1.08 & 1.07 & 1.06 & 1.06 & 1.06 \\
\hline$R_{S, \text { Dark }}^{I}, \mathrm{OM}_{\mathrm{M}}$ & 11 & 1.6 & 0.6 & 0.3 & 0.08 & 0.02 & 0.0032 \\
\hline$R_{S, \text { Light }}^{I}, \mathrm{OM}_{\mathrm{M}}$ & 18 & 1.6 & 0.5 & 0.3 & 0.08 & 0.02 & 0.002 \\
\hline$R_{S, \text { Dark }}^{I}, \mathrm{OM}^{\prime} \cdot \mathrm{cm}^{2}$ & $2.15 \cdot 10^{-6}$ & $2.83 \cdot 10^{-6}$ & $4.24 \cdot 10^{-6}$ & $5.89 \cdot 10^{-6}$ & $6.28 \cdot 10^{-6}$ & $6.25 \cdot 10^{-6}$ & $6.28 \cdot 10^{-6}$ \\
\hline$C^{I}, \Pi \Phi$ & 0.019 & 0.153 & 0.589 & 1.594 & 6.378 & 25.279 & 158.970 \\
\hline$\tilde{C}^{I}, \Pi \Phi / \mathrm{cm}^{2}\left(10^{4}\right)$ & 9.7 & 8.7 & 8.33 & 8.11 & 8.1 & 8.09 & 8.04 \\
\hline$I_{S, r \text { Light }}^{I}, \mathrm{~A}$ & $3.0 \cdot 10^{-10}$ & $7.0 \cdot 10^{-10}$ & $1.2 \cdot 10^{-9}$ & $2.0 \cdot 10^{-9}$ & $5.0 \cdot 10^{-9}$ & $1.0 \cdot 10^{-8}$ & $2.5 \cdot 10^{-8}$ \\
\hline$I_{S, r \text { Dark }}^{I}, \mathrm{~A}$ & $2.0 \cdot 10^{-12}$ & $4.0 \cdot 10^{-12}$ & $6.0 \cdot 10^{-12}$ & $8.0 \cdot 10^{-12}$ & $9.0 \cdot 10^{-12}$ & $1.0 \cdot 10^{-11}$ & $1.3 \cdot 10^{-11}$ \\
\hline$I_{S, f, \text { Dark }}^{I}, \mathrm{~A}$ & $3.0 \cdot 10^{-15}$ & $2.5 \cdot 10^{-14}$ & $7.0 \cdot 10^{-14}$ & $2.5 \cdot 10^{-13}$ & $7.0 \cdot 10^{-13}$ & $3.0 \cdot 10^{-12}$ & $2.0 \cdot 10^{-11}$ \\
\hline$I_{S, f, \text { Light }}^{I}, \mathrm{~A}$ & $1.5 \cdot 10^{-15}$ & $1.2 \cdot 10^{-14}$ & $6.0 \cdot 10^{-14}$ & $1.5 \cdot 10^{-13}$ & $7.0 \cdot 10^{-13}$ & $2.0 \cdot 10^{-12}$ & $1.0 \cdot 10^{-11}$ \\
\hline$I_{\mathrm{Ph}}^{I}, \mathrm{~A}$ & $3.0 \cdot 10^{-10}$ & $7.0 \cdot 10^{-10}$ & $1.2 \cdot 10^{-9}$ & $2.0 \cdot 10^{-9}$ & $5.0 \cdot 10^{-9}$ & $1.0 \cdot 10^{-8}$ & $2.5 \cdot 10^{-8}$ \\
\hline$\Delta U_{f, \text { Dark }}^{I}, \mathrm{~B}$ & 0.20 & 0.16 & 0.11 & 0.09 & 0.08 & 0.06 & 0.02 \\
\hline$U_{\mathrm{Ph}}^{I}, \mathrm{~B}$ & 0.33 & 0.29 & 0.27 & 0.25 & 0.23 & 0.22 & 0.2 \\
\hline$\xi_{I}, \mathrm{MKM}^{-1}$ & 0.8 & 0.267 & 0.133 & 0.08 & 0.04 & 0.02 & 0.008 \\
\hline$\tilde{\beta}_{U}^{i}$, отн. ед. & 0.700 & 0.616 & 0.573 & 0.531 & 0.488 & 0.467 & 0.425 \\
\hline$\tilde{\beta}_{I}^{i}$, отн. ед. & $2.65 \cdot 10^{-5}$ & $6.19 \cdot 10^{-5}$ & $1.06 \cdot 10^{-4}$ & $1.77 \cdot 10^{-4}$ & $4.42 \cdot 10^{-4}$ & $8.85 \cdot 10^{-4}$ & $2.21 \cdot 10^{-3}$ \\
\hline$\varphi_{\text {GaAs-Surface, }}$ эB & 0.87 & 0.88 & 0.92 & 0.89 & 0.85 & 0.91 & 0.86 \\
\hline$\varphi_{\mathrm{GaAs}-\mathrm{Contact}}^{I},{ }^{\mathrm{B}}$ & 0.558 & 0.528 & 0.508 & 0.398 & 0.295 & 0.189 & 0.124 \\
\hline$\varphi_{I}^{*},{ }^{*} \mathrm{~B}$ & 0.558 & 0.528 & 0.508 & 0.398 & 0.295 & 0.189 & 0.124 \\
\hline$l_{I}^{*} \cdot 10^{4}, \mathrm{~cm}$ & 5.6 & 10.6 & 13.4 & 19 & 20 & 21 & 22 \\
\hline$l_{C I}^{*} \cdot 10^{4}, \mathrm{~cm}$ & 2.4 & 4.5 & 9.1 & 11 & 18.9 & 24 & 26.3 \\
\hline$E_{I, \max }^{*}\left(10^{5}\right), \mathrm{B} / \mathrm{M}$ & 0.62 & 0.65 & 0.67 & 1.08 & 1.12 & 1.16 & 1.19 \\
\hline$E_{I}^{L}\left(10^{5}\right), \mathrm{B} / \mathrm{M}$ & 4.53 & 4.50 & 4.48 & 4.07 & 4.03 & 3.99 & 3.96 \\
\hline
\end{tabular}

Расчеты электростатических параметров осуществлялись в системе СГСЭ (сантиметр-грамм-секунда электростатическая).

\section{3. Результаты}

\section{1. Контакты I-типа}

Относительные изменения основных аддитивных параметров прямых и обратных ВАХ в зависимости от диаметра контактов $I$-типа $D_{I}$ сохраняют известную закономерность - с уменьшеием $D_{I}$ значение $\varphi_{b m, f(r) \text {,Dark }}^{I}$ уменьшается, а $n_{\text {Dark }}^{I}$ и $R_{S \text {, Dark }}^{I}$, наоборот, увеличиваются (рис. 1,a). При этом уменьшение удельных значений последовательных сопротивлений $\tilde{R}_{\text {Dark }}^{I}$ и увеличение удельных значений емкостей $\tilde{C}_{\text {Dark }}^{I}$ с уменьшением диаметра контактов $D_{I}$ (табл. 1) не подчиняются известным представлениям и могут быть объяснены повышенной проводимостью периферийной области [17] и размерными эффектами [18], которые в данной работе рассматриваться не будут. Превышение обратных $I_{S, r}^{I} \equiv I_{S, r \text {, Dark }}^{I}$ токов насыщения над прямыми $I_{S, f}^{I} \equiv I_{S, f \text {, Dark, a так- }}^{I}$ же наличие „мертвых“ $\Delta U_{f}^{I} \equiv \Delta U_{f \text {, Dark }}^{I}$ областей, харак- теризующих отсутствие прямых токов на начальных участках прямых ВАХ, в общем случае укладывается в рамки сформированных в $[8,9]$ представлений о влиянии встроенного электрического поля периферии $E_{l}^{I}$ на процесс токопрохождения в контактах М-П с БШ. Согласно [19], уменьшение диаметра $D_{I}$ (увеличение значений $\xi_{I}$ ) приводит к увеличению встроенного электрического поля периферии $E_{l}^{I}$, вектор которого сонаправлен с вектором электрического поля $E_{W}$ в ОПЗ периферийной области контакта. В результате суперпозиции $E_{l}^{I}$ и $E_{W}$ результирующее электрическое поле в области интерфейса $\mathrm{M}-$ П увеличивается, что приводит к заметному понижению измеряемой (эффективной) высоты барьера $\varphi_{b m, r, \text { Dark }}^{I}$ для обратных ВАХ и увеличению термополевой эмиссии. Для прямых ВАХ наблюдается обратный эффект. Из-за того что электрическое поле прямого смещения направлено противоположно встроенному электрическому полю $E_{l}^{I}$, наблюдается незначительное увеличение эффективной высоты барьера $\varphi_{b m, f, \text { Dark }}^{I}$ (табл. 1).

Освещение включенных в электрическую цепь контактов I-типа приводит к появлению на их обкладках фотоэдс $U_{\mathrm{Ph}}^{I}$, проявляющейся на прямых световых $\mathrm{BAX}$ в увеличении „мертвых“ областей $\Delta U_{f \text {, Light }}^{I}=U_{\mathrm{Ph}}^{I}$, а на 
обратных — в значительном увеличении интенсивности обратных токов насыщени $I_{S, r, \text { Light }}^{I}$ за счет возникновения фототока $I_{\mathrm{Ph}}^{I}$ (рис. $\left.1, b\right)$ :

$$
I_{S, r, \mathrm{Light}}^{I}=I_{S, r}^{I}+I_{\mathrm{Ph}}^{I} .
$$

При этом хорошо видно, что наличие внешнего обратного смещения способствует некоторому увеличению фототока, а прямое - к незначительному его уменьшению.

При наличии освещения увеличение параметра $\xi_{I}$ для контактов $I$-типа приводит к увеличению фотоэдс $U_{\mathrm{Ph}}^{I}$ и уменьшению фототока $I_{\mathrm{Ph}}^{I}$. Столь сильное влияние освещения не может не сказаться и на относительных изменениях значений основных аддитивных параметров статических прямых и обратных световых BAX: $I_{S, f(r), \text { Light }}^{I}$, $\varphi_{b m, f(r), \text { Light }}^{I}, n_{\text {Light }}^{I}, R_{S \text {,Light }}^{I}, C^{I}$ и др. (табл. 1). Увеличение $D_{I}$ от 5 до 500 мкм сопровождается увеличением значений $\varphi_{b m, f \text {, Light }}^{I}$ от 0.907 до 0.918 эВ, которые в среднем незначительно превышают аналогичные значения $\varphi_{b m, f}^{I}$ темновых $\mathrm{BAX}\left(0.871-0.894\right.$ эВ). Значения $\varphi_{b m, r, \text { Light }}^{I}$, характеризующие высоту барьера обратных световых $\mathrm{BAX}$, также увеличиваются с увеличением диаметра контактов $(0.592-0.715$ эВ) и при этом заметно меньше значений $\varphi_{b m, r, \text { Dark }}^{I} \equiv \varphi_{b m, r}^{I}(0.721-0.890$ эВ), что и определяет значительный рост обратных токов $I_{S, r, \text { Light }}^{I}$ $\left(3 \cdot 10^{-10}-2.5 \cdot 10^{-8} \mathrm{~A}\right.$. При этом значения $I_{S, r, \text { Light }}^{I}$ на несколько порядков превышают значения $I_{S, r, \text { Dark }}^{I}$, разность которых, согласно (10), и определяет значение величины фототока $I_{\mathrm{Ph}}^{I}=I_{S, r, \text { Light }}^{I}-I_{S, r, \text { Dark}}^{I}$.

Значения показателей идеальности световых ВАX $n_{\text {Light }}^{I}$ уменьшаются от 1.11 до 1.06 при увеличении $D_{I}$ и в среднем превышают значения аналогичных параметров темновых ВАХ. Значения $R_{S, \text { Light }}^{I}$ ведут себя практически аналогично значениям темновых $R_{S}^{I}$.

Изменение значений относительных величин $\tilde{\beta}_{I}^{I}$ и $\tilde{\beta}_{U}^{I}$ в зависимости от $D_{I}$ связано с поведением значений величин $I_{\mathrm{Ph}}^{I}$ и $U_{\mathrm{Ph}}^{I}$. Поэтому увеличение параметра $\xi_{I}$ при уменьшении $D_{I}$ приводит к увеличению значений $\tilde{\beta}_{U}^{I}$ и уменьшению значений $\tilde{\beta}_{I}^{I}$. При этом величина $\tilde{\beta}_{U}^{I}$ имеет близкие к единице значения $\sim 0.7$, а $\tilde{\beta}_{I}^{I}-$ на несколько порядков меньшие значения (табл. 1).

\section{2. Контакты $K$-типа}

В случае контактов $K$-типа увеличение параметра $\xi_{K}$ происходит не за счет уменьшения площади, как для контактов $I$-типа, а за счет увеличения периметра $P_{K}$. В частности, из рис. $2, a$ видно, что ВАХ контактов при токах, превышающих $10^{-9} \mathrm{~A}$, проходят в непосредственной близости друг от друга - практически совпадают. Так происходит потому, что контакты $K$-типа имеют одинаковую площадь. Различия в поведении ВАХ, связанные с влиянием периметра, наиболее ярко проявляются при токах менее $<10^{-9} \mathrm{~A}$. При таких токах наблюдаются небольшие различия в токах насыщения, эффективных высотах барьеров и темновых областей прямых ВАХ. Увеличение параметра $\xi_{K}$ приводит к незначительному уменьшению прямых токов насыщения $I_{S, f, \text { Dark, }}^{K}$ сопровождающееся незначительным увеличением эффективных высот барьеров прямых ВАХ $\varphi_{b m, f, \text { Dark }}^{K}$ от 0.894 до 0.907 эВ (рис. 2, a). Одновременное увеличение значений $\varphi_{b m, f, \text { Dark }}^{K}$ и $n_{\text {Dark }}^{K}$ с ростом $\xi_{K}$ характерно только для контактов $K$-типа, что, видимо, связано с особенностями влияния электростатического поля периферии $E_{l}^{K}$ на электростатическую систему таких контактов (табл. 2). Для контактов остальных типов, как будет показано далее, увеличение $\varphi_{b m, f, \text { Dark }}^{\xi}$ сопровождается обычным уменьшением значений $n_{\text {Dark }}^{\xi}$. При этом наблюдается незначительное $(\sim 0.04 \mathrm{~B})$ увеличение значений „мертвых“ областей $\Delta U_{f, \text { Dark }}^{K}$. Как видно из рис. $2, a$ и табл. 2, последовательное сопротивление $R_{S, \text { Dark }}^{K}$ практически не зависит от периметра контактов $P_{K}$. Это указывает на то, что периферия имеет сравнительно небольшую долю в общей проводимости контакта. Как и для контактов $I$-типа, наблюдается сильное различие значений прямых $I_{S, f, \text { Dark }}^{K}$ и обратных $I_{S, r, \text { Dark }}^{K}$ токов насыщения, вызванное, как следует из $[8,9]$, влиянием встроенного электрического поля периферии $E_{l}^{K}[9]$. В отличие от предыдущего случая, увеличение значений $\xi_{K}$ сопровождается уменьшением эффективных высот барьеров обратных $\mathrm{BAX} \varphi_{b m, r, \text { Dark }}^{K}$, что и приводит к относительному росту обратных токов насыщения $I_{S, r, \text { Dark }}^{K}$.

Обратим внимание на емкость контактов $K$-типа. Если проводимость периферии составляет малую долю в общей проводимости контакта, то в полной емкости контакта может составлять заметную часть - до $10 \%$ и более. Так, увеличение значений параметра $\xi_{K}$ на порядок приводит к увеличению удельной емкости контактов $\tilde{C}_{\text {Dark }}^{K}$ более чем на $12 \%$. В случае круглых контактов $I$-типа, для подобного $(\sim 17 \%)$ увеличения значений удельной емкости $\tilde{C}_{\text {Dark }}^{I}$ параметр $\xi_{I}$ необходимо было увеличить более чем на 2 порядка.

Освещение контактов $K$-типа (рис. $2, b)$ приводит к возникновению фотоэдс и $U_{\mathrm{Ph}}^{K}$ и фототока $I_{\mathrm{Ph}}^{K}$ в цепи, что сопровождается значительным (более чем на 5 порядков) относительно темновых ВАХ увеличением интенсивности обратных токов насыщения $I_{S, r, \text { Light }}^{K}$ и в $\sim 2.8$ раза относительным увеличением значений границ „мертвых“ областей $\Delta U_{f, \text { Light }}^{K}$ [9]. Так, увеличение значений параметра $\xi_{K}$ более чем на порядок, от 0.04 до $0.4 \mathrm{M \kappa м}^{-1}$, приводит к аналогичному (более чем в 10 раз) относительному увеличению фототока, в то время как относительные значения фотоэдс $U_{\mathrm{Ph}}^{K}$ увеличились только на $\sim 30 \%$ (табл. 2). Из табл. 2 видно, что под влиянием освещения практически все приборные характеристики контактов $K$-типа претерпевают заметные изменения. Увеличение значений $\xi_{K}$ для прямых световых ВАХ сопровождается более быстрым (по сравнению с темновыми ВАХ) увеличением значений эффективных высот барьеров $\varphi_{b m, f, \text { Light }}^{K}$ И соответственно уменьшением прямых световых токов 
Таблица 2. Параметры световых („Light“) и темновых („Dark“) BAX контактов $K$-типа

\begin{tabular}{|c|c|c|c|c|c|c|}
\hline$k$ & 6, круг & 5 & 4 & 3 & 2 & 1 \\
\hline Периметр $P_{K}$, мкм & 314.16 & 354.49 & 472.70 & 825.40 & 1590.80 & 3151.60 \\
\hline$\varphi_{b m, f, \text { Dark }}^{K}$, эB & 0.894 & 0.897 & 0.900 & 0.903 & 0.907 & 0.907 \\
\hline$\varphi_{b m, f, \text { Light }}^{K}$, эB & 0.894 & 0.903 & 0.908 & 0.910 & 0.913 & 0.915 \\
\hline$\varphi_{b m, r, \text { Dark }}^{K}, \ni \mathrm{B}$ & 0.757 & 0.747 & 0.739 & 0.733 & 0.733 & 0.733 \\
\hline$\varphi_{b m, r, \text { Light }}^{K},{ }^{K}$ ЭB & 0.549 & 0.542 & 0.537 & 0.519 & 0.495 & 0.473 \\
\hline$n_{\text {Dark }}^{K}$ & 1.05 & 1.06 & 1.06 & 1.07 & 1.08 & 1.09 \\
\hline$n_{\text {Light }}^{K}$ & 1.03 & 1.03 & 1.02 & 1.01 & 1.00 & 1.00 \\
\hline$R_{S, \text { Dark }}^{K}$, OM & 3.0 & 3.0 & 3.0 & 3.0 & 3.0 & 3.0 \\
\hline$R_{s q, \mathrm{Dark}}^{K}, \mathrm{OM} \cdot \mathrm{cm}^{2}$ & $2.35 \cdot 10^{-4}$ & $2.35 \cdot 10^{-4}$ & $2.35 \cdot 10^{-4}$ & $2.35 \cdot 10^{-4}$ & $2.35 \cdot 10^{-4}$ & $2.35 \cdot 10^{-4}$ \\
\hline$R_{S, \text { Light }}^{K}, \mathrm{OM}$ & 3.0 & 3.4 & 3.7 & 3.9 & 4.4 & 6.0 \\
\hline$C_{\text {Dark }}^{K}, \Pi \Phi$ & 5.874 & 5.885 & 5.964 & 6.148 & 6.549 & 6.708 \\
\hline$\tilde{C}_{\text {Dark }}^{K}, \Pi \Phi / \mathrm{cm}^{2}\left(10^{4}\right)$ & 7.5 & 7.5 & 7.6 & 7.8 & 8.4 & 8.5 \\
\hline$I_{S, r, \text { Dark }}^{K}, \mathrm{~A}$ & $2.0 \cdot 10^{-10}$ & $3.0 \cdot 10^{-10}$ & $4.0 \cdot 10^{-1}$ & $05.0 \cdot 10^{-10}$ & $5.0 \cdot 10^{-10}$ & $5.0 \cdot 10^{-10}$ \\
\hline$I_{S, r, \text { Light }}^{K}, \mathrm{~A}$ & $6.0 \cdot 10^{-7}$ & $8.0 \cdot 10^{-7}$ & $1.0 \cdot 10^{-6}$ & $2.0 \cdot 10^{-6}$ & $5.0 \cdot 10^{-6}$ & $1.13 \cdot 10^{-5}$ \\
\hline$I_{\mathrm{Ph}}^{K}, \mathrm{HA}$ & $6.0 \cdot 10^{-7}$ & $8.0 \cdot 10^{-7}$ & $1.0 \cdot 10^{-6}$ & $2.0 \cdot 10^{-6}$ & $5.0 \cdot 10^{-6}$ & $1.13 \cdot 10^{-5}$ \\
\hline$I_{S, f, \text { Dark }}^{K}, \mathrm{~A}$ & $1.0 \cdot 10^{-12}$ & $9.0 \cdot 10^{-13}$ & $8.0 \cdot 10^{-1}$ & $37.0 \cdot 10^{-13}$ & $6.0 \cdot 10^{-13}$ & $6.0 \cdot 10^{-13}$ \\
\hline$I_{S, f, \text { Light }}^{K}, \mathrm{~A}$ & $9.0 \cdot 10^{-13}$ & $8.1 \cdot 10^{-13}$ & $7.3 \cdot 10^{-13}$ & $6.2 \cdot 10^{-13}$ & $5.5 \cdot 10^{-13}$ & $5.0 \cdot 10^{-13}$ \\
\hline$\Delta U_{f, \text { Dark }}^{K}, \mathrm{~B}$ & 0.13 & 0.13 & 0.14 & 0.14 & 0.15 & 0.17 \\
\hline$U_{\mathrm{Ph}}^{K}, \mathrm{~B}$ & 0.35 & 0.37 & 0.38 & 0.4 & 0.42 & 0.45 \\
\hline$\xi_{K}, \mathrm{MKM}^{-1}$ & 0.040 & 0.045 & 0.060 & 0.105 & 0.203 & 0.401 \\
\hline$\tilde{\tilde{\beta}}_{U}^{K}$, отн.ед. & 0.743 & 0.786 & 0.807 & 0.849 & 0.892 & 0.955 \\
\hline$\tilde{\beta}_{I}^{K}$, отн.ед. & 0.053 & 0.071 & 0.088 & 0.177 & 0.442 & 1 \\
\hline$\varphi_{\text {GaAs-Surface, }}$ ЭB & 0.96 & 1.04 & 0.98 & 0.97 & 0.99 & 0.96 \\
\hline$\varphi_{\text {Au-Contact }}^{K}, \ni \mathrm{B}$ & 0.19 & 0.29 & 0.39 & 0.77 & 0.79 & 0.82 \\
\hline$\varphi_{K}^{*}$, эB & 0.19 & 0.29 & 0.39 & 0.77 & 0.79 & 0.82 \\
\hline$l_{K}^{*}$, Мкм & 6.5 & 15.5 & 18 & 25 & 40 & 47.8 \\
\hline$l_{C K}^{*}$, МКM & 10.5 & 10.4 & 13 & 4.9 & 3.5 & 3.2 \\
\hline$E_{K, \max }^{*}\left(10^{5}\right), \mathrm{B} / \mathrm{M}$ & 1.89 & 1.58 & 1.47 & 1.44 & 1.42 & 1.35 \\
\hline$E_{l}^{K}\left(10^{5}\right), \mathrm{B} / \mathrm{M}$ & 3.26 & 3.57 & 3.68 & 3.71 & 3.73 & 3.8 \\
\hline
\end{tabular}

насыщения $I_{S, f \text {, Light }}^{K}$, уменьшением значений $n_{\text {Light }}^{K}$ до 1.00 и увеличением практически в 2 раза последовательных сопротивлений $R_{S, \text { Light }}^{K}$ (табл. 2).

Из табл. 2 видно, что для контактов $K$-типа значения $\tilde{\beta}_{U}^{K}$ и $\tilde{\beta}_{I}^{K}$ гораздо ближе к оптимальным, чем аналогичные значения контактов $I$-типа. При этом значения $\tilde{\beta}_{I}^{K}=1$ имеют максимальные среди исследуемых контактов значения.

Таким образом, мы видим, что увеличение протяженности периметра $P_{K}$ при постоянной площади $S_{K}=$ const приводит к увеличению как значений фотоэдс $U_{\mathrm{Ph}}^{K}$, так и силы фототока $I_{\mathrm{Ph}}^{K}$.

\section{3. Контакты $L$-типа}

В случае контактов $L$-типа увеличение значений параметра $\xi_{L}$ происходит только за счет уменьшения их площади. Поведение темновых и световых ВАХ контактов $L$-типа (рис. 3 ) заметно отличается от поведения темновых и световых ВАХ контактов I- (рис. 1) и $K$-типов (рис. 2). Относительное различие более чем в 48 раз площадей контактов $L$-типа $\left(S_{L 1} / S_{L 7}=48\right)$, несмотря на одинаковый периметр, приводит соответ- ственно и к сильному различию в значениях аддитивных параметров их статических темновых и световых ВАХ.

Для темновых ВАХ уменьшение значений $\xi_{L}$ (увеличение площади контактов) приводит к увеличению значений эффективных высот барьеров как прямых

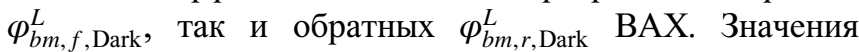
обратных $I_{S, r \text {, Dark }}^{L}$ токов насыщения, как и в предыдущих двух случаях для контактов $I$ - и $K$-типов, значительно отличаются от прямых $I_{S, f \text {, Dark }}^{L}$. При этом значения прямых токов насыщения $I_{S, f \text {,Dark }}^{L}$ увеличиваются с увеличением площади, а обратных $I_{S, r \text {, Dark }}^{L}$, наоборот, уменьшаются (табл. 3), что не является тривиальным фактом и сильно отличается от поведения ВАХ контактов других типов. Обращает на себя внимание и то, что, несмотря на значительную (более чем в 48 раз) разницу в площадях контактов, относительные изменения значений обратных токов насыщения $I_{S, r \text {, Dark }}^{L}$ очень незначительны. При этом, как и для контактов I-типа, контакты с меньшей площадью имеют меньшие значения токов насыщения $I_{S, f \text {, Dark }}^{L}$ и большие значения $\Delta U_{f, \text { Dark }}^{L}$. Существенные отличия наблюдаются в поведении обратных токов насыщения $I_{S, r \text {, Dark. }}^{L}$ С уменьшением площади они не уменьшаются, как для контактов I-типа, а, наоборот, 
Таблица 3. Параметры световых („Light“) и темновых („Dark“) BAX контактов $L$-типа

\begin{tabular}{|c|c|c|c|c|c|c|c|}
\hline 1 & 7 & 6 & 5 & 4 & 3 & 2 & 1 \\
\hline Площадь $S_{l}$, мкм $^{2}$ & 596 & 891 & 1475 & 2900 & 5600 & 10400 & 28648 \\
\hline$\varphi_{b m, f \text { Dark }}^{l}$, эB & 0.915 & 0.918 & 0.920 & 0.913 & 0.917 & 0.922 & 0.929 \\
\hline$\varphi_{b m, f, \text { Light }}^{l},{ }^{\prime} \mathrm{B}$ & 0.918 & 0.921 & 0.923 & 0.927 & 0.927 & 0.925 & 0.928 \\
\hline$\varphi_{b m, r, \text { Dark }}^{l},{ }^{\prime} \mathrm{B}$ & 0.708 & 0.721 & 0.738 & 0.758 & 0.779 & 0.800 & 0.923 \\
\hline$\varphi_{b m, r, \text { Light }}^{l}$, эB & 0.453 & 0.465 & 0.479 & 0.499 & 0.517 & 0.535 & 0.563 \\
\hline$n_{\text {Dark }}^{l}$ & 1.056 & 1.056 & 1.038 & 1.056 & 1.056 & 1.038 & 1.038 \\
\hline$n_{\text {Lifght }}^{l}$ & 1.038 & 1.038 & 1.020 & 1.004 & 1.004 & 1.004 & 1.005 \\
\hline$R_{S, \text { Dark }}^{l}$, OM & 14.0 & 11.70 & 0.28 & 0.20 & 0.15 & 0.10 & 0.05 \\
\hline$\tilde{R}_{S, \text { Dark }}$, Ом $\cdot \mathrm{cm}^{2}$ & $8.34 \cdot 10^{-5}$ & $1.04 \cdot 10^{-4}$ & $4.13 \cdot 10^{-6}$ & $5.80 \cdot 10^{-6}$ & $8.40 \cdot 10^{-6}$ & $1.04 \cdot 10^{-5}$ & $1.43 \cdot 10^{-5}$ \\
\hline$R_{S, \text { Light }}^{l}, \mathrm{OM}$ & 14.60 & 12.00 & 0.50 & 0.40 & 0.30 & 0.20 & 0.15 \\
\hline$C_{\text {Dark }}^{l}, \Pi \Phi$ & 1.08 & 1.31 & 1.75 & 2.83 & 4.80 & 8.20 & 21.5 \\
\hline$\tilde{C}_{\text {Dark }}^{l}, \Pi \Phi / \mathrm{cm}^{2}\left(10^{4}\right)$ & 18 & 15 & 12 & 0.9 & 8.5 & 7.9 & 7.5 \\
\hline$I_{S, r, \text { Dark }}^{l}, \mathrm{~A}$ & $1.0 \cdot 10^{-10}$ & $9.0 \cdot 10^{-11}$ & $8.0 \cdot 10^{-11}$ & $7.0 \cdot 10^{-11}$ & $6.0 \cdot 10^{-11}$ & $5.0 \cdot 10^{-11}$ & $4.5 \cdot 10^{-11}$ \\
\hline$I_{S, r, \text { Light }}^{l}, \mathrm{~A}$ & $1.9 \cdot 10^{-6}$ & $1.8 \cdot 10^{-6}$ & $1.7 \cdot 10^{-6}$ & $1.6 \cdot 10^{-6}$ & $1.5 \cdot 10^{-6}$ & $1.4 \cdot 10^{-6}$ & $1.3 \cdot 10^{-6}$ \\
\hline$I_{\mathrm{Ph}}^{l}, \mathrm{HA}$ & $1.9 \cdot 10^{-6}$ & $1.8 \cdot 10^{-6}$ & $1.7 \cdot 10^{-6}$ & $1.6 \cdot 10^{-6}$ & $1.5 \cdot 10^{-6}$ & $1.4 \cdot 10^{-6}$ & $1.3 \cdot 10^{-6}$ \\
\hline$I_{S, f, \text { Dark }}^{l}, \mathrm{~A}$ & $3.4 \cdot 10^{-14}$ & $4.5 \cdot 10^{-14}$ & $7.0 \cdot 10^{-14}$ & $1.8 \cdot 10^{-13}$ & $3.0 \cdot 10^{-13}$ & $4.5 \cdot 10^{-13}$ & $1.2 \cdot 10^{-12}$ \\
\hline$I_{S, f, \text { Light }}^{l}, \mathrm{~A}$ & $3.0 \cdot 10^{-14}$ & $4.0 \cdot 10^{-14}$ & $6.2 \cdot 10^{-14}$ & $1.0 \cdot 10^{-13}$ & $2.0 \cdot 10^{-13}$ & $4.0 \cdot 10^{-13}$ & $1.0 \cdot 10^{-12}$ \\
\hline$\Delta U_{f, \text { Dark }}^{l}, \mathrm{~B}$ & 0.198 & 0.197 & 0.187 & 0.181 & 0.161 & 0.133 & 0.123 \\
\hline$U_{\mathrm{Ph}}^{l}, \mathrm{~B}$ & 0.471 & 0.456 & 0.445 & 0.428 & 0.411 & 0.400 & 0.371 \\
\hline$\underbrace{\xi_{l}}_{\sim}, \mathrm{MKM}^{-1}$ & 1.007 & 0.673 & 0.407 & 0.207 & 0.107 & 0.058 & 0.021 \\
\hline$\tilde{\beta}_{\sim}^{l}$, отн.ед. & 1 & 0.968 & 0.945 & 0.909 & 0.873 & 0,849 & 0.878 \\
\hline$\tilde{\beta}_{I}^{l}$, отн.ед. & 0.168 & 0.159 & 0.150 & 0.141 & 0.132 & 0.123 & 0.115 \\
\hline$\varphi_{\text {GaAs-Surface }}$, эB & 0.84 & 0.89 & 0.93 & 0.91 & 0.92 & 0.87 & 0.94 \\
\hline$\varphi_{\text {Au-Contact }}, \ni \mathrm{B}$ & 0.6 & 0.59 & 0.58 & 0.56 & 0.45 & 0.25 & 0.18 \\
\hline$\varphi_{L}^{*},{ }_{\ni} \mathrm{B}$ & 0.6 & 0.59 & 0.58 & 0.56 & 0.45 & 0.25 & 0.18 \\
\hline$l_{L}^{*}$, мкм & 36 & 33 & 32 & 26.8 & 26.5 & 26.3 & 26.2 \\
\hline$l_{C L}^{*}, \mathrm{MKм}$ & 1.5 & 2.5 & 8 & 18 & 23 & 36 & 40.3 \\
\hline$E_{L, \max }^{*} \cdot 10^{-5}, \mathrm{~B} / \mathrm{M}$ & 0.55 & 0.59 & 0.67 & 0.79 & 0.97 & 1.07 & 1.20 \\
\hline$E_{l}^{L} \cdot 10^{-5}, \mathrm{~B} / \mathrm{M}$ & 4.6 & 4.56 & 4.48 & 4.36 & 4.18 & 4.08 & 3.95 \\
\hline
\end{tabular}

увеличиваются, что также не является тривиальным фактом. В данном случае уменьшение площади контакта в $\sim 48$ раз приводит к увеличению значений $\Delta U_{f, \text { Dark }}^{L}$ на $\sim 38 \%$, что еще раз указывает на сильное влияние периферии на электростатическую систему контактов M-П с БШ. Показатель идеальности $n_{\text {Dark }}^{L}$ ведет себя обычным образом - его значения несколько выше, чем в случаях с контактами $I$ - и $K$-типов, и уменьшаются с увеличением площади $S_{L}$.

Как и для контактов I-типа, уменьшение $\xi_{L}$ сопровождается ростом значений удельного сопротивления $\tilde{R}_{S \text {,Dark }}^{L}$ и уменьшением значений удельной емкости $\tilde{C}_{\text {Dark }}^{L}$, что может быть объяснено соответственно заметным влиянием периферийной области $[16,17]$ и размерными эффектами [18].

Основные особенности в поведении параметров темновых ВАХ контактов $L$-типа $\left(P_{L}=\right.$ const $)$ сохраняются и для соответствующих параметров их световых ВАХ: контактам с меньшей площадью $S_{L}$ соответствуют большие значения не только фотоэдс $U_{\mathrm{Ph}}^{L}$, но и фототока $I_{\mathrm{Ph}}^{L}$ (рис. 3). Значения $\Delta U_{f \text {, Light }}^{L}$ увеличиваются почти в 3 раза, а значения $I_{S, r \text {, Light }}^{L}-$ более чем на 4 порядка (табл. 3).
Для световых BAX контактов $L$-типов изменение аддитивных приборных характеристик в зависимости от значений $\xi_{L}$ происходит аналогично изменению аддитивных приборных характеристик их темновых BAX: с увеличением площади контактов (уменьшением $\xi_{L}$ ) значения $\varphi_{b m, f \text {, Light }}^{L}, \varphi_{b m, r \text {,Light }}^{L}$ и $I_{S, f, \text { Light }}^{L}$ увеличиваются, а $I_{S, r, \text { Light }}^{L}, n_{\text {Light }}^{L}$ и $R_{S, \text { Light }}^{L}$, наоборот, уменьшаются (табл. 3 ). При этом значения высот барьеров и последовательных сопротивлений в среднем больше, а показатели идеальности меньше значений соответствующих приборных характеристик темновых ВАХ. Близкие значения световых обратных токов насыщения $I_{S, r \text {, Light }}^{L}$, как следствие, фототоков $I_{\mathrm{Ph}}^{L}$ можно связать с одинаковым периметром $P_{L}$ периферии контактов. Примечательно, что для данного типа контактов значительное увеличение значений $\xi_{L}$ (уменьшение площади $S_{L}$ ) практически не сказывается на относительном увеличении значений $I_{S, r \text { Light }}^{L}$, но приводит к заметному относительному увеличению $\Delta U_{f \text {, Dark }}^{L}$ и соответственно фотоэдс $U_{\mathrm{Ph}}^{L}$ (таб. 3).

Полученные результаты нетривиальным образом указывают на значительное влияние периферии на токопрохождение в контактах М-П с БШ и, как следствие, на 
Таблица 4. Параметры световых („Light“) и темновых („Dark“) BAX контактов $M$-типа

\begin{tabular}{|c|c|c|c|c|c|c|}
\hline$m$ & 1 & 2 & 3 & 4 & 5 & 6 \\
\hline Длина $b_{m}$, мкм & 40 & 80 & 160 & 320 & 640 & 1280 \\
\hline$\varphi_{b m, f, \text { Dark }}^{m}$, эB & 0.913 & 0.913 & 0.913 & 0.918 & 0.920 & 0.925 \\
\hline$\varphi_{b m, f, \text { Light }}^{m},{ }^{\prime} \mathrm{B}$ & 0.900 & 0.902 & 0.902 & 0.904 & 0.907 & 0.908 \\
\hline$\varphi_{b m, r, \text { Dark }}^{m}$, эB & 0.762 & 0.762 & 0.774 & 0.788 & 0.795 & 0.788 \\
\hline$\varphi_{b m, r, \text { Light }}^{m}$, эB & 0.508 & 0.512 & 0.514 & 0.516 & 0.518 & 0.513 \\
\hline$n_{\text {Dark }}^{m}$ & 1.055 & 1.055 & 1.055 & 1.055 & 1.038 & 1.038 \\
\hline$n_{\text {Light }}^{m}$ & 1.055 & 1.055 & 1.021 & 1.004 & 1.000 & 1.001 \\
\hline$R_{S, \text { Dark }}^{m}, \mathrm{OM}$ & 0.20 & 0.20 & 0.30 & 0.40 & 0.45 & 0.50 \\
\hline$\tilde{R}_{S, \text { Dark }}^{m}, \mathrm{OM}^{\prime} \cdot \mathrm{cm}^{2}$ & $1.6 \cdot 10^{-7}$ & $3.2 \cdot 10^{-6}$ & $9.6 \cdot 10^{-6}$ & $2.56 \cdot 10^{-5}$ & $5.76 \cdot 10^{-5}$ & $1.28 \cdot 10^{-4}$ \\
\hline$R_{S, \text { Light }}^{m}$, OM & 0.16 & 0.15 & 0.20 & 0.30 & 0.45 & 0.55 \\
\hline$C_{\text {Dark }}^{m}, \Pi \Phi$ & 0.91 & 1.65 & 2.82 & 5.45 & 10.51 & 20.40 \\
\hline$\tilde{C}_{\text {Dark }}^{m}, \Pi \Phi / \mathrm{cm}^{2}\left(10^{4}\right)$ & 11.4 & 10.3 & 8.8 & 8.5 & 8.2 & 8.0 \\
\hline$I_{S, r, \text { Dark }}^{m}, \mathrm{~A}$ & $1.7 \cdot 10^{-11}$ & $3.4 \cdot 10^{-11}$ & $4.3 \cdot 10^{-11}$ & $5.0 \cdot 10^{-11}$ & $7.5 \cdot 10^{-11}$ & $2.0 \cdot 10^{-10}$ \\
\hline$I_{S, r, \text { Light }}^{m}, \mathrm{~A}$ & $3.1 \cdot 10^{-7}$ & $5.2 \cdot 10^{-7}$ & $9.8 \cdot 10^{-7}$ & $1.8 \cdot 10^{-6}$ & $3.3 \cdot 10^{-6}$ & $8.0 \cdot 10^{-6}$ \\
\hline$I_{\mathrm{Ph}}^{m}, \mathrm{HA}$ & $3.1 \cdot 10^{-7}$ & $5.2 \cdot 10^{-7}$ & $9.8 \cdot 10^{-7}$ & $1.8 \cdot 10^{-6}$ & $3.3 \cdot 10^{-6}$ & $8.0 \cdot 10^{-6}$ \\
\hline$I_{S, f, \text { Dark }}^{m}, \mathrm{~A}$ & $5.0 \cdot 10^{-14}$ & $1.0 \cdot 10^{-13}$ & $2.0 \cdot 10^{-13}$ & $3.2 \cdot 10^{-13}$ & $6.0 \cdot 10^{-13}$ & $1.0 \cdot 10^{-12}$ \\
\hline$I_{S, f, \text { Light }}^{m}, \mathrm{~A}$ & $8.0 \cdot 10^{-14}$ & $1.5 \cdot 10^{-13}$ & $3.0 \cdot 10^{-13}$ & $5.5 \cdot 10^{-13}$ & $1.0 \cdot 10^{-12}$ & $2.0 \cdot 10^{-12}$ \\
\hline$\Delta U_{f, \text { Dark }}^{m}, \mathrm{~B}$ & 0.13 & 0.13 & 0.13 & 0.14 & 0.14 & 0.14 \\
\hline$U_{\mathrm{Ph}}^{m}, \mathrm{~B}$ & 0.42 & 0.42 & 0.42 & 0.42 & 0.42 & 0.42 \\
\hline$\xi_{m}, \mathrm{MKM}^{-1}$ & 0.15 & 0.125 & 0.113 & 0.106 & 0.103 & 0.102 \\
\hline$\beta_{U}^{m}$, отн. ед. & 0.892 & 0.892 & 0.892 & 0.892 & 0.892 & 0.892 \\
\hline$\beta_{I}^{m}$, отн. ед. & 0.027 & 0.046 & 0.087 & 0.159 & 0.280 & 0.707 \\
\hline$\varphi_{\text {GaAs-Surface, }}$ эB & 0.85 & 0.87 & 0.85 & 0.92 & 0.95 & 0.95 \\
\hline$\varphi_{\text {Au-Contact }}^{m}, \ni \mathrm{B}$ & 0.52 & 0.49 & 0.46 & 0.51 & 0.5 & 0.48 \\
\hline$\varphi_{M}^{*}$, эB & 0.52 & 0.49 & 0.46 & 0.51 & 0.5 & 0.48 \\
\hline$l_{M}^{*}$, мкм & 30.4 & 29.8 & 31.2 & 30.5 & 30.1 & 30.1 \\
\hline$l_{C M}^{*}$, МКм & 8.9 & 8.2 & 8.3 & 8.3 & 8.0 & 8.2 \\
\hline$E_{M, \max }^{*} \cdot 10^{-4}, \mathrm{~B} / \mathrm{M}$ & 9.29 & 9.19 & 8.28 & 8.31 & 8.32 & 8.29 \\
\hline$E_{l}^{M} \cdot 10^{-5} \mathrm{~B} / \mathrm{M}$ & 4.22 & 4.23 & 4.32 & 4.32 & 4.32 & 4.32 \\
\hline
\end{tabular}

их вольтовую $\tilde{\beta}_{U}^{L}$ и токовую $\tilde{\beta}_{I}^{L}$ фоточувствительности. Из табл. 3 видно, что для контактов $L$-типа величина $\tilde{\beta}_{U}^{L}=1$ имеет наибольшее относительное значение, в то время как значения величин $\tilde{\beta}_{I}^{L}$ заметно уступают аналогичным значениям контактов $K$-типа. В случае контактов $L$-типа фиксация периметра $P_{L}=$ const приводит и к фиксации значений фототока $I_{\mathrm{Ph}}^{L} \approx$ const. При этом уменьшение площади $S_{L}$ приводит к заметному относительному увеличению значений фотоэдс $U_{\mathrm{Ph}}^{L}$.

\section{4. Контакты М-типа}

Прямоугольные контакты $M$-типа построены таким образом, что их ширина $a=$ const много меньше их длины $b_{M}$, которая выбиралась в качестве изменяемого параметра. В этом случае увеличение $b_{M}$ приводит почти к прямо пропорциональному с точностью до $a$ линейному увеличению периметра $P_{M}$ и площади $S_{M}$ ( $\xi_{M}=P_{M} / S_{M} \approx$ const). Из-за того что $a-$ конечная величина, наблюдается тенденция к небольшому $(0.15-0.102)$ уменьшению значений $\xi_{M}$ с ростом $b_{M}$ с последующим выходом на насыщение 0.1. В данных экспериментах величину $\xi_{M}$ будем считать постоянной с точностью $0.10+0.05$ мкм $^{-1}$. В общем случае чем меньше $a$, тем точнее будет выполняться равенство $\xi_{M}=$ const. Так как $\xi_{M}=$ const, ожидается, что эффекты, за которые ответственно относительное изменение периметра и площади контактов, не должны претерпевать сильных изменений. Это обстоятельство должно помочь нам отделить эффекты, связанные с относительным влиянием встроенного электрического поля периферии $E_{l}^{M}$, от эффектов, за которые ответственна площадь контакта $S_{M}$. Действительно, поведение темновых и световых BAX контактов $M$-типа (рис. 4) существенным образом отличается от поведения темновых и световых ВАХ контактов других типов.

Основные отличия заключаются в том, что независимо от площади контактов все темновые ВАХ имеют практически одинаковые значения $\Delta U_{f \text {, Dark }}^{M}$, но разные прямые $I_{S, f \text {,Dark }}^{M}$ и обратные $I_{S, r, \text { Dark }}^{M}$ токи насыщения. При этом, как и во всех предыдущих случаях, значения обратных токов насыщения $I_{S, r, \text { Dark }}^{m}$ на несколько порядков превышают прямые токи насыщения $I_{S, f \text {, Dark }}^{m}$ и увеличиваются с увеличением длины контактов $b_{M}$ (линейным увеличением $S_{M}$ и $P_{M}$ ). Хорошо видно, что увеличение длины $b_{M}$ приводит к незначительному росту значений $\varphi_{b m, f \text {, Dark }}^{M}, \varphi_{b m, r, \text { Dark }}^{M}, I_{S, f \text {, Dark }}^{M} I_{S, r, \text { Dark }}^{M}$, а значений $n_{\text {Dark }}^{M}$ и $R_{S, \text { Dark }}^{m}-$ к незначительному умень- 
шению. Увеличение значений $R_{S, \text { Dark }}^{m}$ с ростом площади золотых контактов связано, по всей вероятности, с увеличением их длины и, как следствие, увеличением их погонного сопротивления. Значения удельных емкостей

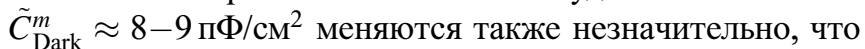
связано с постоянным значением $\xi_{M} \approx$ const.

Для световых ВАХ наблюдается значительный (более чем на 5 порядков) рост обратных токов и в несколько раз (с 0.13 до $0.42 \mathrm{~B}$ ) одновременное увеличение

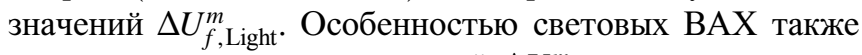
является постоянство значений $\Delta U_{f \text {, Light }}^{m}$ прямых световых $\mathrm{BAX}$ и соответственно значений $U_{\mathrm{Ph}}^{m}$. Увеличение длины $b_{M}$, как и для темновых $\mathrm{BAX}$, приводит к незначительному росту значений $\varphi_{b m, f \text {, Light },}^{M} \varphi_{b m, r \text { Light }}^{M}$, $I_{S, f \text {, Light }}^{M}$ и $I_{S, r \text {, Light }}^{M}$, а значений $n_{\text {Light }}^{M}-$ к уменьшению. Незначительные увеличения значений $R_{S \text {, Light }}^{M}$ с ростом площади контактов, по всей вероятности, обусловлены увеличением погонного сопротивления металлизации золотых контактов с увеличением их длины $b_{M}$.

Из табл. 4 видно, что при практически постоянном значении $\xi_{M}$ величины $\tilde{\beta}_{U}^{M}$ также имеют близкие к 1 постоянные значения. Для контактов $M$-типа фиксация значений параметра $\xi_{M}$ приводит к фиксации значений фотоэдс $U_{\mathrm{Ph}}^{M}$. При этом увеличение периметра, как и в случае контактов $K$-типа, приводит к увеличению силы фототока $I_{\mathrm{Ph}}^{M}$. Дополнительные эксперименты показали, что увеличение значения $\xi_{M}$ приводит к быстрому увеличению значения $\tilde{\beta}_{U}^{M}$. Таким образом, корреляция значений параметров $\tilde{\beta}_{U}^{M}$ и $\xi_{M}$ указывает на связь фотоэдс не только с периметром, но и с площадью контакта.

Исходя из вышеизложенного можно заключить, что наибольшую вольтовую $\tilde{\beta}_{U}^{\xi}$ и токовую $\tilde{\beta}_{I}^{\xi}$ фоточувствительности имеют контакты $K$ - и $L$-типов, для которых значения $\xi_{\xi}$ максимальны. Для повышения токовой фоточувствительности $\beta_{I}^{\xi}$ необходимо увеличение протяженности периметра $P_{\xi}$, а для повышения вольтовой $\beta_{U}^{\xi}-$ значения параметра $\xi_{\xi}$. Исходя из этого можно предложить тривиальный способ повышения эффективности преобразования световой энергии в электрическую (увеличения значений $\beta_{I}^{\xi}$ и $\beta_{U}^{\xi}$ ) контактами $\mathrm{M}-\Pi$ с БШ. Из геометрии дробных размерностей известно, что у фрактальных фигур отношение периметра к площади может быть сколь угодно большим. В пределе $\lim _{P \rightarrow \infty} P$, а следовательно, и значение $\xi \rightarrow \infty$, где $\underset{S=\text { const }}{d \mathbf{r} \rightarrow 0}$

$d \mathbf{r}-$ радиус-вектор измерительного масштаба. Таким образом, понятно, что для максимального увеличения значений $\xi_{\xi}$ и увеличения значений $\beta_{I}^{\xi}$ и $\beta_{U}^{\xi}$ периметру контактов металл-полупроводник с барьером Шоттки $K$ - и $L$-типов заданной площади необходимо придать фрактальную форму с максимально возможным количеством уровней подобия. Далее будет поазано, что при этом необходимо учитывать размеры латеральных неоднородностей в распределении электрических полей периферии вокруг контактов.

\section{4. Обсуждение экспериментальных результатов}

Физическая природа прямых и обратных темновых токов насыщения темновых ВАХ контактов М-П с БШ была подробно описана нами в [8]. Для описания физической природы наблюдаемых фотогальванических эффектов необходимо рассмотреть не только общие закономерности, но и отличия, связанные, согласно вышеизложенному, как с абсолютными значениями $\xi_{\xi}$, так и со способом их нахождения.

На первый взгляд может показаться, что физические механизмы наблюдаемых фотогальванических эффектов легко объясняются на основе известных компактных моделей (эквивалентных электрических схем) контактов М-П с БШ. Например, увеличение периметров $P_{K}$ и $P_{M}$ для контактов $K$ - и $M$-типов, согласно (табл. 2 и 4), сопровождается практически прямо пропорциональным увеличением значений $I_{\mathrm{Ph}}^{K}$ и $I_{\mathrm{Ph}}^{M}$, что согласуется с законом Ома. Для контактов $L$-типа $\left(P_{L}=\right.$ const), для которых периметр был постоянным, значение фототока $I_{\mathrm{Ph}}^{K}$ также было постоянным и практически не зависело от площади контактов. Таким образом, прямо пропорциональное увеличение фототока $I_{\mathrm{Ph}}^{\xi} \mathrm{c}$ увеличением протяженности периметра $P_{\xi}$, согласно закону Ома, выглядит логичным.

Совершенно иная ситуация наблюдается с фотоэдс $U_{\mathrm{Ph}}^{\xi}$. Изменение значений фотоэдс $U_{\mathrm{Ph}}^{\xi}$ нельзя связать с изменением периметра $P_{\xi}$. Например, для контактов $L$-типа, для которых периметр постоянен, значения фотоэдс $U_{\mathrm{Ph}}^{L}$ изменяются в достаточно широких пределах, а для контактов $M$-типа, наоборот, увеличение периметра никак не влияет на значение фотоэдс $U_{\mathrm{Ph}}^{M}=$ const.

Нельзя связать изменение значений фотоэдс $U_{\mathrm{Ph}}^{\xi}$ и с изменением площади контактов $S_{\xi}$. Так, значительное уменьшение площади контактов никак не влияет на значение фотоэдс $U_{\mathrm{Ph}}^{M}$ контактов $M$-типа, в то время как для контактов I-типа, наоборот, - приводит к увеличению значений $U_{\mathrm{Ph}}^{I}$. Для контактов $K$-типа увеличение значений фотоэдс $U_{\mathrm{Ph}}^{L}$ наблюдается вообще при постоянной площади $S_{K}=$ const контактов.

Определенную корреляцию значений $U_{\mathrm{Ph}}^{\xi}$ можно наблюдать со значениями параметра $\xi_{\xi}=P_{\xi} / S_{\xi}$. Согласно вышеизложенному, увеличение значений $\xi_{\xi}$ приводит к непропорциональному росту значений фотоэдс $U_{\mathrm{Ph}}^{\xi}$. При постоянном значении параметра $\xi_{M}=$ const значения фотоэдс $U_{\mathrm{Ph}}^{M}=$ const также постоянны. Для определения функциональной зависимости $F=U_{\mathrm{Ph}}^{\xi}\left(\xi_{\xi}\right)$ необходимо проведение более подробных исследований.

Для более подробного исследования физических механизмов возникновения вентильного фотоэффекта в контактах металл-полупроводник с барьером Шоттки рассмотрим подробно их физическую модель (далее просто - модель). Напомним, что контакт М-П с барьером Шоттки (БШ) бесконечной площади $(S \rightarrow \infty)$ лишен аддитивных геометрических свойств и, как след- 
ствие, не имеет аддитивных характеристик, его емкость бесконечна, а сопротивление барьера стремится к нулю и в пределе при $S \rightarrow \infty$ не зависит от смещения, т.е. не имеет нелинейных выпрямляющих (диодных) характеристик [20]. Это согласуется с утверждением [20], что физическое состояние $\Psi$ макроскопической системы контакта М-П с БШ приобретает нелинейные аддитивные электрические характеристики только после формирования границы (периферии) контакта и появления у него аддитивных геометрических свойств. Таким образом, состояние контакта $\Psi\left(\theta_{j}\right)$ будет характеризоваться набором аддитивных параметров $\theta_{j}$, таких, например, как периметр $\theta_{1} \equiv P$, площадь $\theta_{2} \equiv S$, параметр $\theta_{3} \equiv \xi$ и т.д. В результате, для того чтобы плоский контакт М-П бесконечной площади приобрел аддитивные геометрические, электрофизические и выпрямляющие нелинейные приборные характеристики (например, ВАХ $I=I(U)$ ), ему необходимо придать какую-нибудь форму, ограничив двумерное топологическое множество контакта внешней границей - периметром $P[20]$. Таким образом, мы видим, что образованная периметром $P$ внешняя граница оказывает важное формирующее влияние как на геометрию плоских контактов М-П с БШ, так и на их аддитивные электрофизические и приборные характеристики. Рассмотрим, благодаря каким физическим механизмам периметр $P$ (геометрия плоского контакта) оказывает столь значительное влияние на электрофизические (в частности, фотоэлектрические) свойства плоских контактов М-П с БШ.

Для начала заметим, что существующие ранее представления об усилении электрического поля ОПЗ $E_{W} \equiv E_{W, r}$ на прямом углу плоского контакта радиуса $r$ (рис. 5,a) [21] не могут объяснить описываемые в данной работе особенности фотогальванических эффектов в контактах $I-, K$-, $L$ - и $M$-типов. Так происходит потому, что максимальное значение модуля электрического поля $\left|E_{W, r}\right|=$ const для заданной системы контактов $\mathrm{M}-П$ постоянно, так как определяется только радиусом закругления $r$ и никак не связано ни с одним из аддитивных параметров контакта: ни с площадью $S_{\xi}$, ни с периметром $P_{\xi}$ (рис. 5, $a$ ).

Нельзя объяснить усиление фотогальванических эффектов и возникающими по периметру контактов Шоттки механическими напряжениями. Известно, что сформированные на свободной поверхности $n$ - $\mathrm{GaAs}(100)$ золотые Au-контакты обладают высокой пластичностью и по этой причине не создают заметных механических нагрузок [17]. Кроме этого, при наличии заметных механических напряжений эквипотенциальные кривые поверхностного потенциала вокруг круглых Аu-контактов, ввиду анизотропии свойств арсенида галлия $\mathrm{GaAs}(100)$, должны были бы проявлять заметное отклонение от радиальной симметрии, как, например, в случае, когда контакты Шоттки окружены слоем диэлектрика [17], чего мы не наблюдаем в экспериментах. Область неоднородного распределения поверхностного потенциала вокруг круглых Аu-контактов (ореол) имеет четкую радиальную симметрию (рис. 6, I, $a$ ) [17].

На возможность влияния периферии на электростатическую систему контактов М-П с БШ впервые было обращено внимание в монографии Мамедова [22]. В частности, там указывалось на то, что вокруг периметра металлических контактов Шоттки существует дополнительное электрическое поле $E_{\text {add }}$, образованное разностью поверхностных потенциалов металлического контакта $\varphi_{m}$ и свободной полупроводниковой поверхности $\varphi_{s}$. Согласно [22], вектор напряженности $E_{\text {add }}$ в области контакта направлен противоположно вектору напряженности электрического поля ОПЗ $E_{W}$.

Как было показано в [9], наличие только $E_{\text {add }}$ не достаточно для объяснения наблюдаемых в работе зависимостей фотоэдс от размеров и формы контактов, так как максимальное значение модуля электрического поля $\left|E_{\text {add }}\right|=$ const для заданной системы М-П постоянно и никак не связано ни с площадью $S_{\xi}$, ни с периметром $P_{\xi}$ контактов.

Согласно [19], вокруг периметра выпрямляющих контактов М-П, кроме постоянного $\left|E_{\text {grad }}\right|=\left|E_{W}\right|=$ const, существует еще выходящее в полупроводник через боковую поверхность ОПЗ и зависящее от площади и периметра (формы) контакта нескомпенсированное электрическое поле $E_{\xi}^{*}$. В нашем случае $E_{\mathrm{grad}}-$ это аналог $E_{\mathrm{add}}$, только направленный в области контакта в противоположную сторону и сонаправлен $E_{W}$. В общем случае для заданной системы $\mathrm{M}-П$ максимальное значение $\left|E_{\text {grad }}\right|=\left|E_{W}\right|$

$$
\left\langle\left|E_{\text {grad }}(\mathbf{r})\right|\right\rangle=\frac{\varphi_{\mathrm{Au}, \text { film }}-\varphi_{S}(x)}{\Delta \mathbf{r}} .
$$

Согласно теореме Остроградского-Гаусса, вектор $E_{\xi}^{*}$ определяется плотностью потока вектора смещения электростатического поля через боковую поверхность области пространственного заряда $Q_{W}^{\xi}[19]$. Вектор $E_{\xi}^{*}$ направлен от контакта по нормали к боковой поверхности ОПЗ в сторону убывания потенциала, а в области контакта - по нормали к плоскости контакта и противоположно сонаправленным векторам $E_{W}$ и $E_{\text {grad. }}$ Площадь боковой поверхности ОПЗ можно представить как $S_{\xi}^{*}=W_{\mathrm{SCh}} \cdot P_{\xi}$, где $W_{\mathrm{SCh}}$ - ширина ОПЗ при нулевом смещении на БШ. Понятно, что при постоянном периметре $P_{L}=$ const и уменьшающейся площади контакта $S_{L} \rightarrow 0$ электрический заряд $Q_{W}^{L}$ будет уменьшаться при неизменной площади боковой поверхности ОПЗ, что, согласно теореме Остроградского-Гаусса, приведет к уменьшению плотности потока вектора смещения электрического поля через боковую поверхность ОПЗ и соответственно к уменьшению модуля $\left|E_{L}^{*}\right|$ (рис. 6, II). Наоборот, при постоянной площади $S_{K}=$ const (контакты $K$-типа) и уменьшающемся периметре $P_{K} \rightarrow$ const заряд $Q_{W}^{K}$ остается постоянным, а площадь боковой поверхности ОПЗ уменьшается. В этом случае плотность потока вектора смещения электрического поля через 


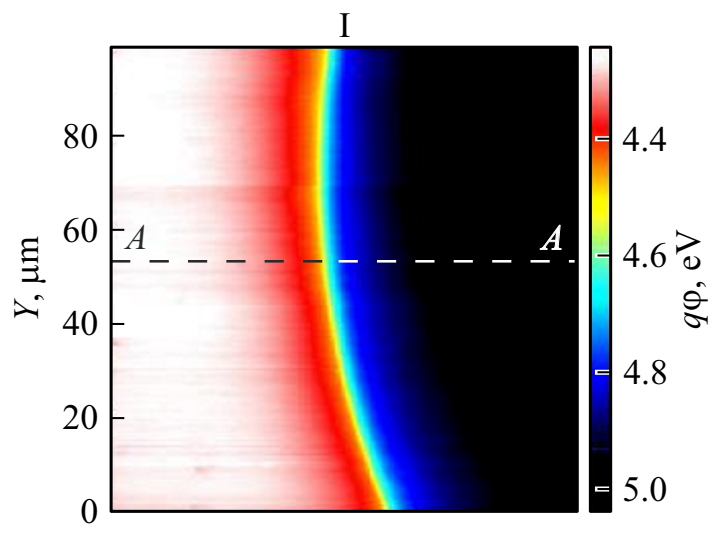

$a$

II
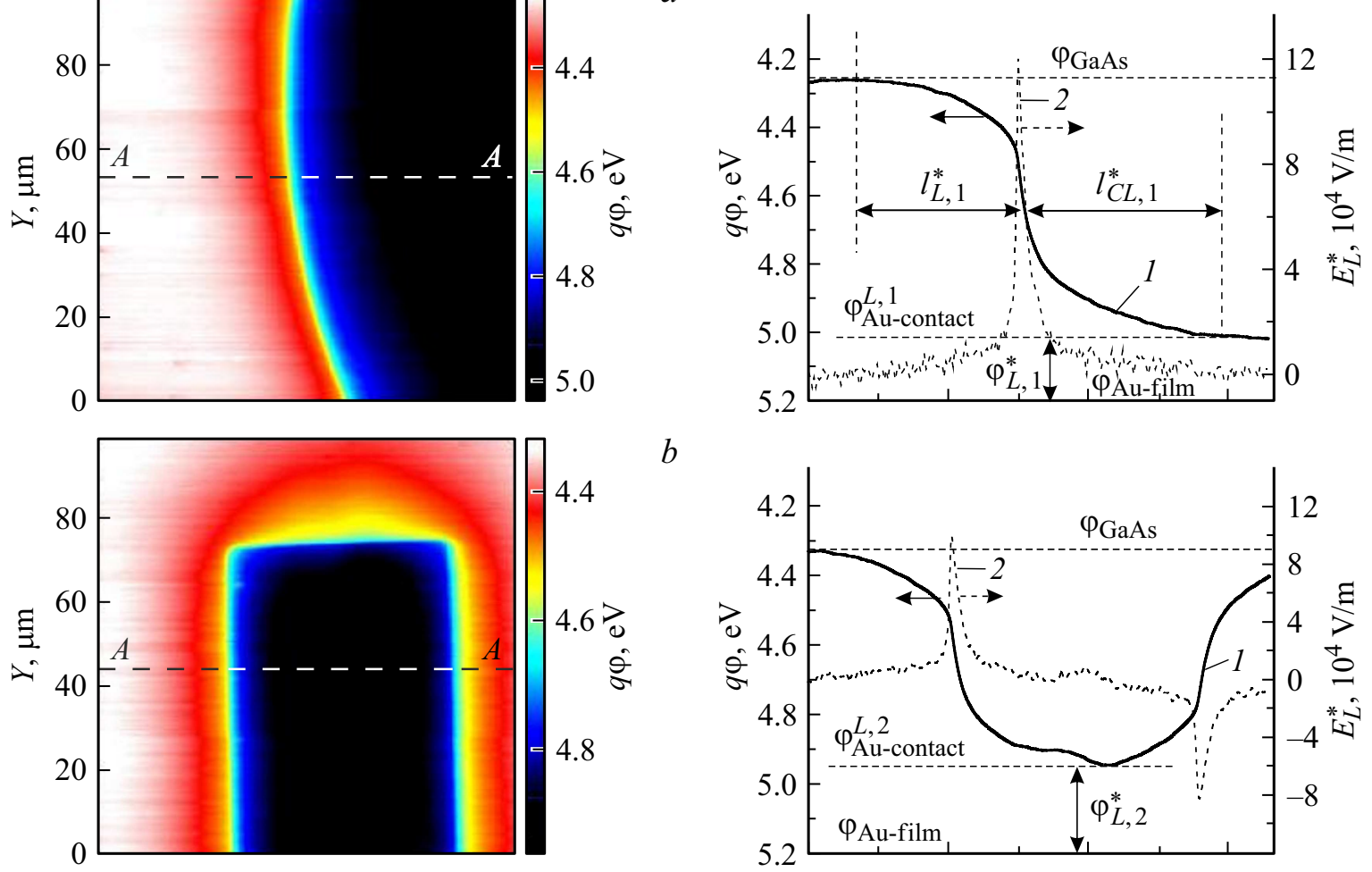

$b$
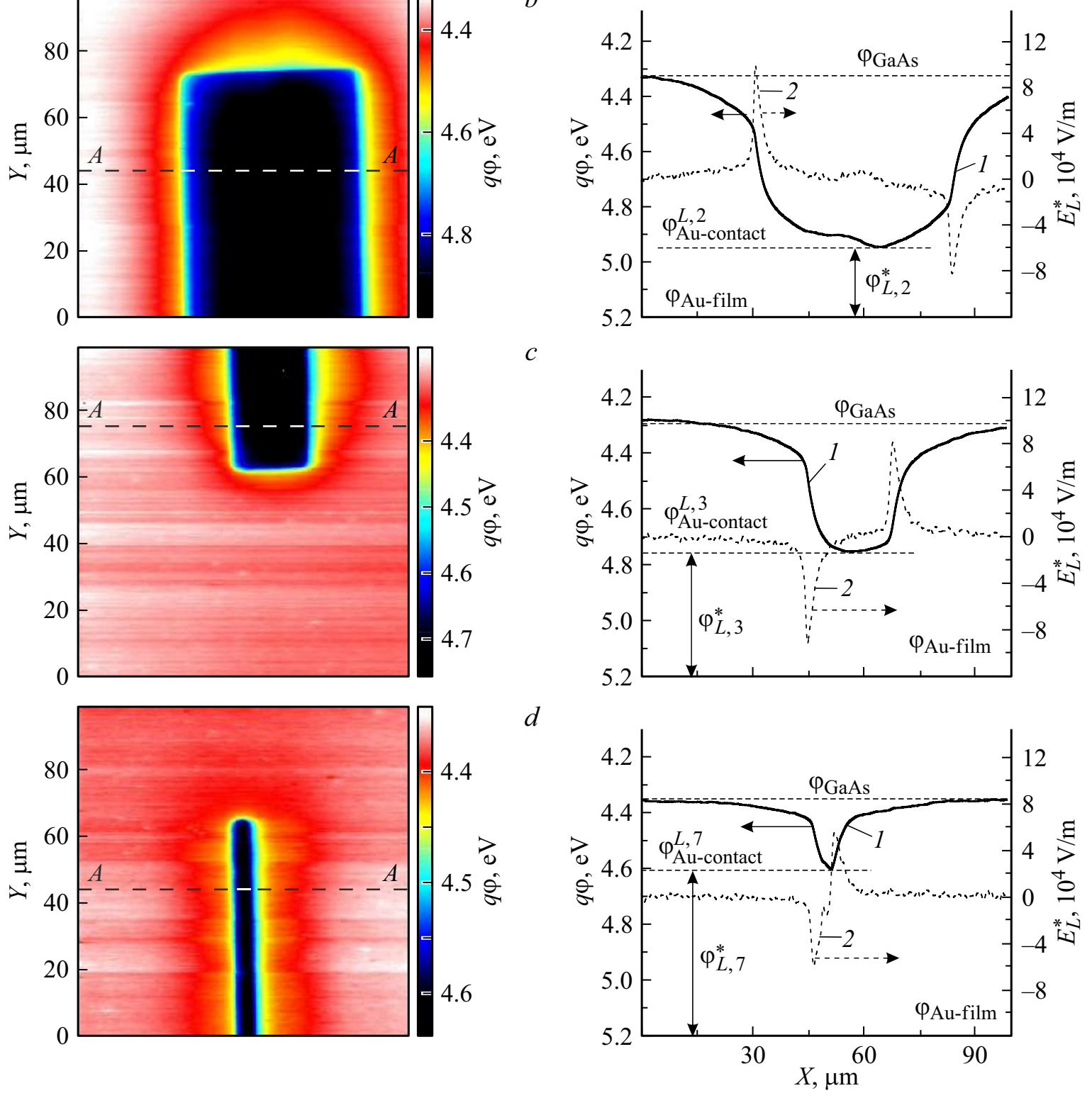

Рис. 6. Двухмерные $\varphi(x, y)-\mathrm{I})$ и одномерные $\varphi(x)-\mathrm{II})$ распределения электростатических потенциалов (работ выхода $q \varphi$ ) поверхности (сплошные кривые 1 ) и электростатических полей $E_{L}^{*}(x)$ (пунктирные кривые 2 ) контактов металл-полупроводник с барьером Шоттки $L$-типа: круглого диаметром $D_{L 1}=190.99$ мкм $(a)$ и прямоугольных $40 \times 260$ мкм $(b), 20 \times 280$ мкм $(c)$ и $2 \times 298$ мкм $(d)$. 
боковую поверхность ОПЗ, наоборот, увеличится, что и приведет к увеличению модуля $\left|E_{K}^{*}\right|$ [9]. Мы видим, что характер изменения значений модуля вектора $E_{\xi}^{*}$ определяется не только абсолютным значением параметpa $\xi_{\xi}$, но и способом его задания. В общем случае всегда $\left|E_{\xi}^{*}\right| \leq\left|E_{\text {grad }}\right|$. Таким образом, вектор результирующего электростатического поля периферии $E_{l}^{\xi}$-контактов М-П с БШ образован суперпозицией вектора постоянного электростатического поля $E_{\text {grad }}$ и зависящего от формы контакта противоположно направленного вектора электростатического поля $E_{\xi}^{*}$ :

$$
E_{l}^{\xi}=E_{\text {grad }}+E_{\xi}^{*}, \text { а для модулей }\left|E_{l}^{\xi}\right|=\left|E_{\text {grad }}\right|-\left|E_{\xi}^{*}\right| .
$$

Так как $\left|E_{\text {grad }}\right| \geq\left|E_{\xi}^{*}\right|$, то в ОПЗ вектор $E_{l}^{\xi}$ сонаправлен с вектором электрического поля ОПЗ $E_{W}$. Для плоских контактов больших площадей $S \rightarrow \infty\left(\xi_{\xi} \rightarrow 0\right),\left|E_{l}^{\xi}\right| \rightarrow 0$ и, согласно (12), модуль $\left|E_{\xi}^{*}\right| \approx\left|E_{\text {grad }}\right|-$ электростатическое поле $\left|E_{\xi}^{*}\right|$ максимально, а $\left|E_{l}^{\xi}\right|$ минимально. Поэтому, как показывают эксперименты, для контактов Шоттки с линейными размерами больше 500 мкм $(D>0.5$ мм $)$ описываемые в работе фотогальванические эффекты практически не наблюдаются. Для контактов с линейными размерами менее 500 мкм влиянием $E_{l}^{\xi}$ уже нельзя полностью пренебрегать. Для плоских контактов малых площадей при $S \rightarrow 0\left(\xi_{\xi} \rightarrow \infty\right)$ модуль $\left|E_{\xi}^{*}\right| \rightarrow 0$ и, согласно (12), $\left|E_{l}^{\xi}\right| \approx\left|E_{\text {grad }}\right|-$ результирующее электрическое поле $E_{l}^{\xi}$ в периферийной области максимально. Так, например, для контактов с линейными размерами менее $<100$ мкм электрическое поле $E_{l}^{\xi}$ уже соизмеримо по модулю с электрическим полем $E_{W}$ (табл. 1-4) и, как будет показано далее, оказывает значительное влияние на электростатическую систему выпрямляющих контактов М-П. В [9] было показано, что именно зависящая от $\xi_{\xi}$ переменная составляющая $E_{\xi}^{*}=E^{*}\left(\xi_{\xi}\right)$ электростатического поля периферии ответственна за наблюдаемые особенности в фотогальванических эффектах.

Рассмотрим термодинамическую систему выпрямляющего контакта металл-полупроводник с барьером Шоттки. Системы не находящиеся в термодинамическом равновесии и удовлетворяющие свойствам топологического смешивания будем называть по отношению друг к другу внешними системами. Поверхностные потенциальные энергии $U_{\text {surf }}$ (электростатические потенциалы, определяющие работу выхода электронов $A=q \varphi$, уровни Ферми $E_{\mathrm{F}}$ ) внешних неравновесных систем имеют разные значения относительно вакуума. Необходимым условием приведения таких систем в состояние термодинамического равновесия является наличие механизмов обмена частицами между ними.

При достаточном сближении между внешними системами могут возникнуть механизмы обмена заряженными частицами. В таких случаях контактирующие части внешних систем за время релаксации $\tau$ придут в состо- яние термодинамического равновесия, характеризующегося выравниванием уровней Ферми $E_{\mathrm{F}}$ в приконтактных областях. При этом в результате переноса и разделения неравновесных электрически заряженных частиц в приконтактных областях, между внешними неравновесными системами возникают встроенные электростатические поля. Такие поля обладают экранирующими свойствами и формируют области пространственных зарядов $W_{\mathrm{SCh}}$, так как препятствуют дальнейшему переносу неравновесных заряженных частиц и переходу остальных частей неравновесных систем в состояние термодинамического равновесия.

С этих позиций в результате обмена неравновесными электронами контактирующий слой ОПЗ полупроводника $W_{\mathrm{SCh}}$ и слой Томаса-Ферми $W_{\mathrm{TF}}$ Аu-контакта Шоттки (рис. 5, $a)$ за время релаксации $\tau=1 /\left(2 \omega f_{T}\right)$ придут в состояние термодинамического равновесия. Как указывалось выше, для используемых контактов $f_{T}>600$ ГГц, что значительно превышает резонансную частоту колебаний балки кантилевера $f_{\text {res }}=400$ КГц. Это означает, что менее чем за одну миллионную периода колебания балки кантилевера система контакта металл-полупроводник с БШ за счет протекания токов насыщения $I_{S, r \text {,Dark }}^{\xi}$ успеет прийти в состояние термодинамического равновесия и выравнивания уровней Ферми $E_{\mathrm{F}, \mathrm{SCh}}=E_{\mathrm{F}, \mathrm{TF}}$ в приконтактных областях Томаса-Ферми и ОПЗ. Из-за того что система пришла в состояние термодинамического равновесия, на ОПЗ уже не будет дополнительно падать напряжение, и значение компенсирующего напряжения $U_{0}=\Delta \varphi=\varphi_{\text {Au-Contact }}-\varphi_{\text {Au-Cantilever }}$ с достаточной точностью будет соответствовать КРП между поверхностными потенциалами Аи-контакта и иглы кантилевера. Падением напряжения на ОПЗ, например, нельзя пренебречь в случаях, когда резонансная частота колебаний балки кантилевера соизмерима с частотой релаксации измеряемой системы, или в случае отсутствия токов насыщения $I_{S, r, \text { Dark }}^{\xi}$. Последнее противоречит теории контакта и практическим результатам. Направление вектора электростатического поля $E_{W}$ в ОПЗ таково, что оно экранирует (препятствует) дальнейшему перемещению электронов и дырок между внешними системами - оставшимися объемами полупроводника и Аu-контакта и их полному переходу в состояние термодинамического равновесия. Из представленных далее результатов АСМ-измерений поверхностных потенциалов контактов $L$ - (рис. 6) и $M$-типов (рис. 7) видно, что работа выхода (уровень Ферми $\left.E_{\mathrm{F}, \text { Au-Contact }}\right)$ выпрямляющих Аu-контактов значительно, на $0.2-0.7$ эВ, отличается от работы выхода (поверхностного уровня Ферми $E_{\mathrm{F}, \mathrm{GaAs}}$ ) окружающей его полупроводниковой поверхности арсенида галлия и от работы выхода сплошной пленки золота $\left(E_{\mathrm{F}, \mathrm{Au}-\mathrm{film}}\right)$. В этом смысле, те области полупроводника и металлического контакта, между которыми не произошел обмен электронами, являются внешними по отношению друг к другу и соответственно будут иметь разный 


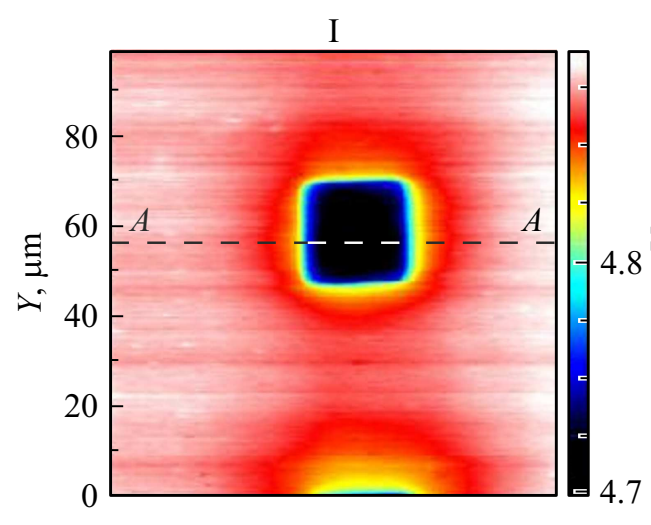

$a$

II
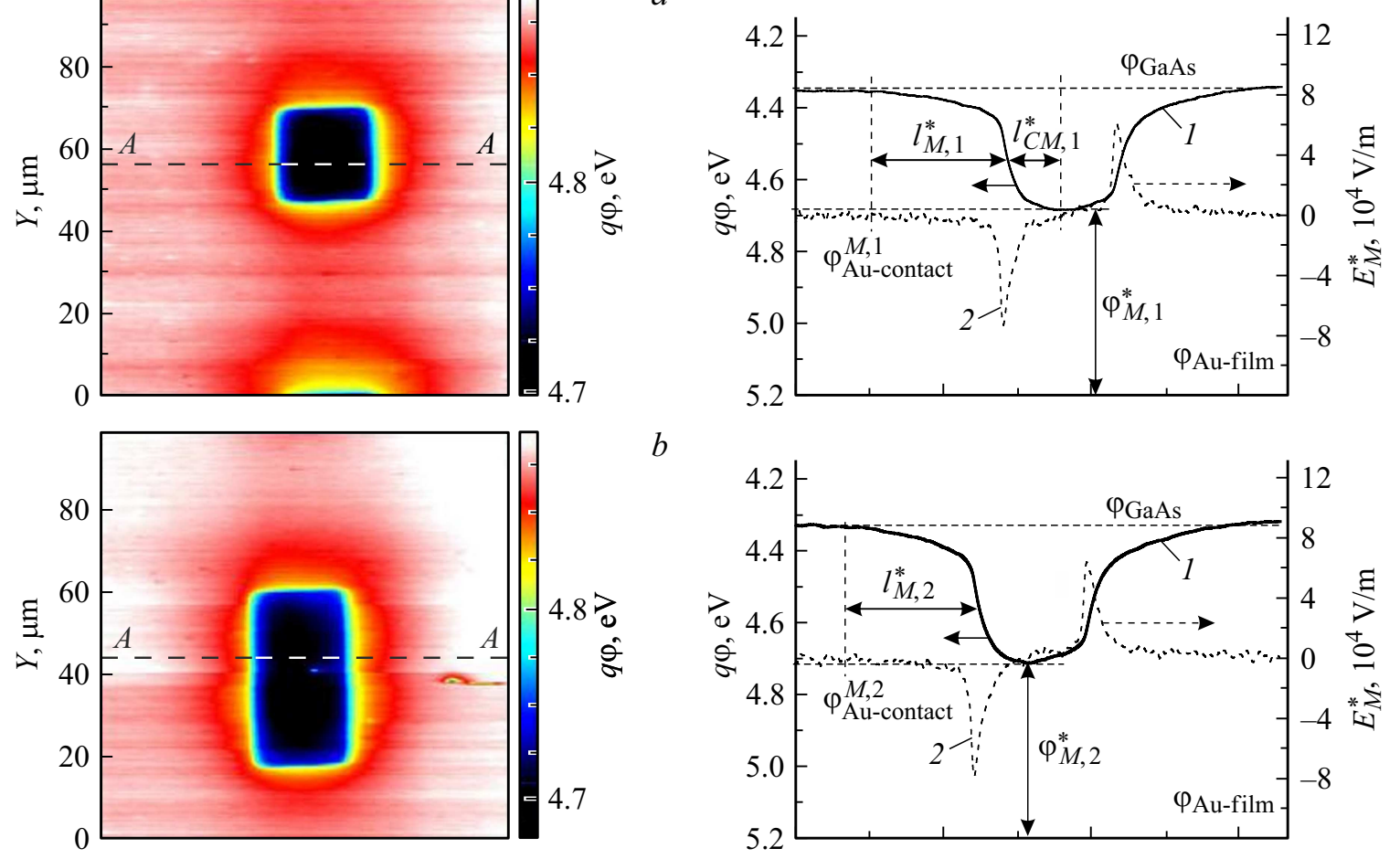

$b$
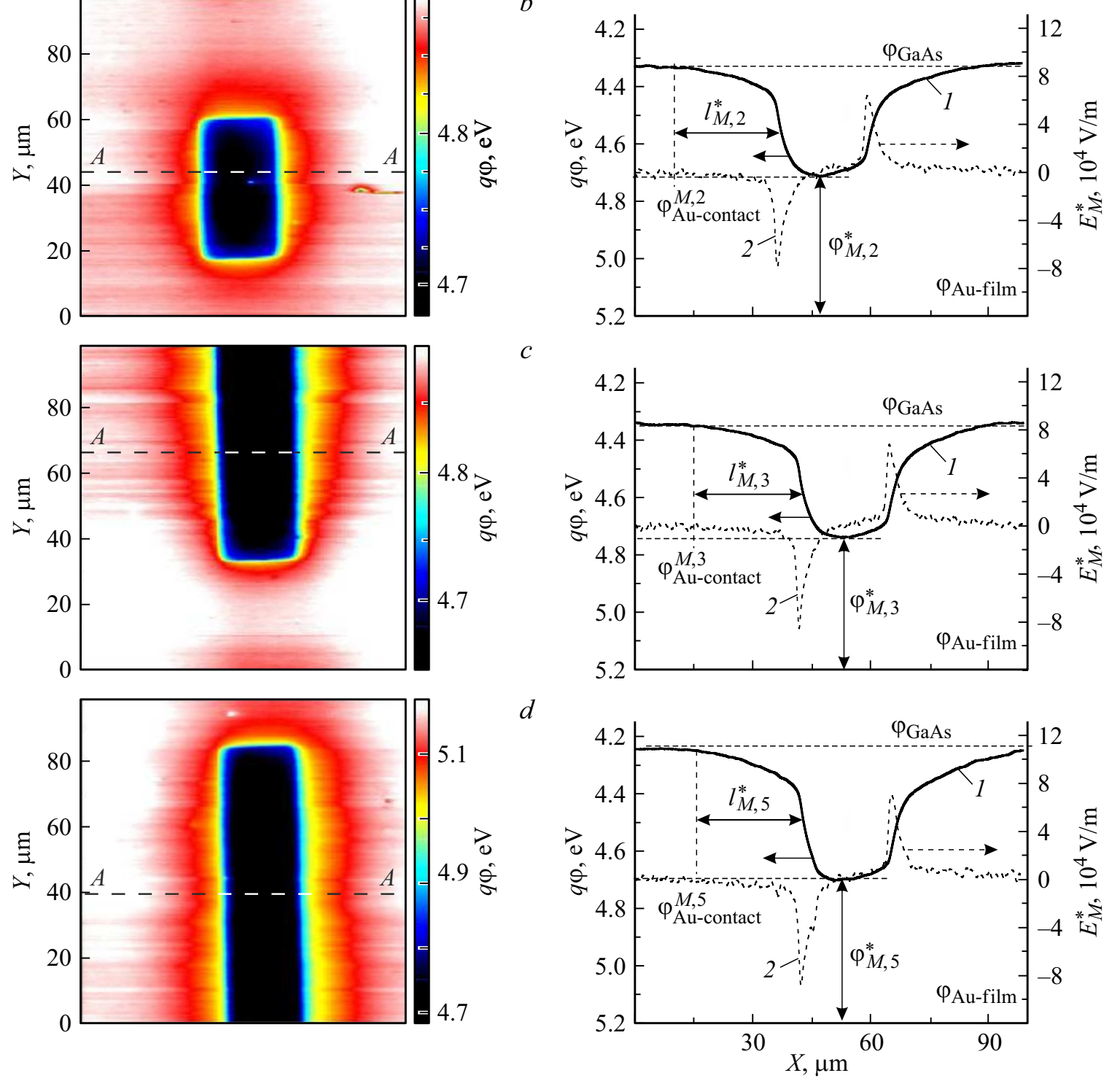

Рис. 7. Двухмерные $\varphi(x, y)-\mathrm{I})$ и одномерные $\varphi(x)-\mathrm{II})$ распределения электростатических потенциалов (работ выхода $q \varphi)$ поверхности (сплошные кривые 1 ) и электростатических полей $E_{M}^{*}(x)$ (пунктирные кривые 2 ) контактов металл-полупроводник с барьером Шоттки $M$-типа: квадратного $20 \times 20$ мкм $(a)$ и прямоугольных $20 \times 40$ мкм $(b), 20 \times 80$ мкм $(c)$ и $20 \times 320$ мкм $(d)$.

поверхностный электростатический потенциал (работу выхода), что мы и наблюдаем в экспериментах (рис. 6 и 7). Экранирующие свойства электростатических по- лей, возникающих в контактирующих неравновесных системах металл-полупроводник, были продемонстрированы нами не только на примере золотых контактов 
на арсениде галлия $[8,9,16,17,19,20]$, но и на примерах платиновых $[23,24]$ и никелевых [25] контактов Шоттки к фосфиду индия $(n$-InP) [24] и нитриду галлия $(n-\mathrm{GaN})[25]$.

Исходя из вышеизложенного внешнее нескомпенсированное электростатическое поле $E_{\xi}^{*}=E^{*}\left(\xi_{\xi}\right)$ участвует в перераспределении частиц и внутренней энергии в окружающем $\mathrm{Au}-$ контакт тонком приповерхностном $n$-слое полупроводника (в данном случае $n$-GaAs) и приводит к изменению его поверхностного электростатического потенциала в приконтактной области. В результате вокруг контакта формируется ореол протяженностью $l_{\xi}^{*}$, в образовании которого принимает участие и нескомпенсированное электростатическое поле $E_{\xi}^{*}$, которое может быть непосредственно измерено методом Кельвина АСМ. Такое измерение возможно потому, что измеряемая поверхность входит в состав электрического контура измерительной схемы атомно-силового микроскопа: земля-ОПЗ-поверхность $-F_{Z}-$ cantilever-земля (graund-SCh-surface $-F_{Z}-$ cantilever-graund) и, согласно условиям термодинамического равновесия, участвует в механизме обмена заряженными частицами с иглой кантилевера через заземленный graund-контакт (рис. $5, a)$. Протяженность $l_{\zeta}^{*}$ будем измерять от геометрической границы контакта до координаты, где потенциал полупроводниковой поверхности составляет $\varphi_{S}=\varphi_{\mathrm{GaAs}}+\left(\varphi_{\mathrm{Au}-\mathrm{Contact}}-\varphi_{\mathrm{GaAs}}\right) / 10$. Из-за низкой концентрации подвижных (не захваченных на поверхностные состояния) носителей электрических зарядов результирующее поле $E_{l}$ способно распространяться за периметр контакта на полупроводниковой поверхности на единицы и десятки микрометров. Как было показано в [20], при перекрытии ореолов между контактами Шоттки возникает заметное электростатическое взаимодействие, приводящее к ослаблению влияния поля периферии $E_{l}$ на электростатическую систему контакта.

Кроме внешнего ореола $l_{\xi}^{*}$ на рис. 5, $b$, показано наличие другой переходной области внутри периметра Аu-контакта - внутренний ореол протяженностью $l_{C \zeta}^{*}$. Протяженность $l_{C \zeta}^{*}$ будем находить аналогичным образом - от геометрической границы контакта до координаты, где потенциал контакта составляет $\varphi_{m}=\varphi_{\text {Au-Contact }}-\left(\varphi_{\text {Au-Contact }}-\varphi_{\mathrm{GaAs}}\right) / 10$. Согласно рис. 6 и 7, внутренний ореол $l_{C \xi}^{*}$ определяет эффективную область контакта (размер периферийной области), в которой влияние $E_{l}^{\xi}$ максимально и, согласно предложенной физической модели, происходит наиболее эффективное преобразование световой энергии в электрическую. Так, например, из табл. 1-4 видно, что в тех областях $l_{C \xi}^{*}$, где электрическое поле $E_{I}^{\xi}$ минимально, значения токовой $\tilde{\beta}_{I}^{\xi}$ и вольтовой $\tilde{\beta}_{U}^{\xi}$ фоточувствительностей также имеют минимальные значения. В тех областях $l_{C \xi}^{*}$, где электрическое поле $E_{l}^{\xi}$ максимально, значения $\tilde{\beta}_{I}^{\zeta}$ и $\tilde{\beta}_{U}^{\zeta}$ принимают максимальные значения.

Преобразование световой энергии в электрическую возможно также и во внутренней области контакта ограниченной ореолом $l_{C \zeta}^{*}$ при достаточно тонкой и полупрозрачной металлизации. Но из-за отсутствия во внутренней области контакта дополнительного электростатического поля $E_{l}^{\xi}$, усиливающего полевую эмиссию электронов, эффективность такого преобразования, как обычно и наблюдается на практике, очень низка. Кроме того, тонкие полупрозрачные металлические контакты обладают большим погонным сопротивлением, что сопровождается дополнительными потерями энергии на джоулево тепло и снижением эффективности преобразования световой энергии в электрическую.

Электростатический потенциал, формируемый другой составляющей электростатического поля периферии $E_{\text {grad, }}$ в АСМ-методе Кельвина напрямую измерить невозможно по причине того, что поле $E_{\text {grad }}$ возникает в другом замкнутом электрическом контуре, не входящем в состав измерительной электрической схемы ACM: contact-поверхность-ОП3-contact (contact-surface-SCh-contact). О наличии $E_{\text {grad }}$ в системе контакта металл-полупроводник можно судить лишь исходя из косвенных результатов измерений значений электростатических потенциалов поверхностей металлических контактов $\varphi_{\text {Au-Contact }}^{\xi}$ и полупроводниковой поверхности $\varphi_{\mathrm{GaAs}}(11)$. Обмен электронами между периферией металлического контакта и окружающей его полупроводниковой поверхностью в контуре contact-поверхность-ОП3-contact происходит по механизмам, обеспечивающим протекание темновых токов насыщения $I_{S, r \text {, Dark }}^{\xi}$.

Несмотря на то что сплошная золотая $\mathrm{Au}$-пленка и

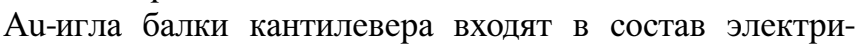
ческого контура измерительной схемы в АСМ-методе Кельвина: земля-поверхность- $F_{Z}-$ cantilever-земля (graund-surface- $-F_{Z}$-cantilever-graund), между ними не будет возникать сила электростатического взаимодействия $F_{Z}=0$ (рис. $5, c$ ). Так происходит потому, что их поверхностные электростатические потенциалы, а следовательно, и уровни Ферми равны между собой $E_{\mathrm{F}, \mathrm{Au}-\text { Cantilever }}=E_{\mathrm{F} \text {, Au-film }}$ (т. е. не являются неравновесными), поэтому и $E_{\mathrm{F} \text {, Au-Cantilever }}-E_{\mathrm{F} \text {, Au-film }}=\Delta \varphi=0$.

Для качественных оценок средних значений модулей электростатических полей $\left\langle\left|E_{\xi}^{*}\right|\right\rangle,\left\langle\left|E_{\text {grad }}\right|\right\rangle$ и $\left\langle\left|E_{l}^{\xi}\right|\right\rangle$, согласно схематическому изображению энергетической диаграммы физической модели (рис. $5, b$ ), можно воспользоваться следующими выражениями:

$$
\begin{gathered}
\left\langle\left|E_{\xi}^{*}\right|\right\rangle=-\frac{\varphi_{\mathrm{GaAs}}-\varphi_{\mathrm{Au}-\mathrm{Contact}}^{\zeta}}{l_{\xi}} \\
\left\langle\left|E_{\mathrm{grad}}\right|\right\rangle=-\frac{\varphi_{\mathrm{GaAs}}-\varphi_{\mathrm{Au}-\text { film }}^{\zeta}}{l_{\xi}^{*}+l_{C \zeta}^{*}}=\mathrm{const}, \\
\left\langle\left|E_{l}^{\xi}\right|\right\rangle=\left\langle\left|E_{\mathrm{grad}}\right|\right\rangle-\left\langle\left|E_{\xi}^{*}\right|\right\rangle=-\frac{\varphi_{\mathrm{Au}-\text { film }}-\varphi_{\text {Au-Contact }}}{l_{\xi}}-\frac{\varphi_{\xi}^{*}}{l_{\xi}},
\end{gathered}
$$

где $l_{\zeta}^{*}$ и $l_{C \zeta}^{*}-$ максимальные линейные размеры внешнего и внутреннего ореолов для заданной системы. Для 
оценок максимальных значений электрических полей $E_{\xi}^{*}$ необходимо проводить дифференцирование потенциала по координате:

$$
E_{\xi}^{*}=0-\frac{d \varphi_{m, s}}{d \mathbf{r}} .
$$

Значение поверхностного потенциала металлического контакта, согласно полученным результатам, а также результатам $[8,9,16,17,19,20]$, в пределе для бесконечно малой площади $S$ будет стремиться к значению потенциала полупроводниковой поверхности:

$$
\lim _{S \rightarrow 0} \varphi_{\mathrm{Au}-\mathrm{Contact}}=\varphi_{\mathrm{GaAs}} .
$$

В этом случае $\left.E_{l}\right|_{E_{\xi}^{*} \rightarrow 0} \rightarrow E_{\text {grad }}^{\xi}$ и электрическое поле периферии будет максимальным и будет оказывать максимальное влияние на электростатическую систему контакта. В другом крайнем случае, когда площадь контакта бесконечна, $\lim _{S \rightarrow \infty} \varphi_{\text {Au-Contact }}=\varphi_{\text {Au-film }}$, что возможно только когда электростатическое поле $\left.E_{l}\right|_{E_{\xi}^{*} \rightarrow E_{\text {grad }}^{\xi}} \rightarrow 0$, т.е. $E_{\xi}^{*}$ максимально компенсирует электростатическое поле $E_{\text {grad }}$.

Максимальное значение модуля $\left|E_{W}\right|=5.15 \cdot 10^{5} \mathrm{~B} / \mathrm{M}$ для заданной системы $\mathrm{Au} / n$-GaAs контакта Шоттки было найдено из решения уравнения Пуассона с учетом сил зеркального изображения при $\varphi_{b}(x=0)=0.93$ эВ. Таким образом, зная $\left|E_{\text {grad }}\right|=\left|E_{W}\right|$ и измерив $E_{\xi}^{*}$, из соотношения (12) можно легко определить и результирующее встроенное электростатическое поле периферии $E_{l}^{\xi}$ (табл. $\left.1-4\right)$. Таким образом, составляющая внешнего электростатического поля периферии $E_{\xi}^{*}=E^{*}\left(\xi_{\xi}\right)$ (рис. 5,b) участвует в формировании наблюдаемых в полученных АСМ-изображениях вокруг выпрямляющих Аu-контактов Шоттки „ореолов““ протяженностью $l_{\xi}=l_{\xi}^{*}+l_{C \xi}[19]$.

Влияние электрических полей периферии на электростатическую систему выпрямляющих контактов М-П хорошо видно на примере прямых измерений АСМ-методом Кельвина электростатических потенциалов контактов $L$ - и $M$-типов. Ожидается, что полученные результаты позволят объяснить наблюдаемые особенности фотогальванических эффектов и найти физическую связь параметра $\xi_{\xi}$ с величиной фотоэдс $U_{\mathrm{Ph}}^{\xi}$.

Из рис. 6 видно, что поверхностный потенциал $\varphi_{\text {Au-Contact }}^{L}$ Au-контактов $L$-типа, как и поверхностные потенциалы контактов $I$ - [19], $K$ - [9] и $M$-типов (рис. 7), значительно отличаются от поверхностного потенциала сплошной пленки золота $\varphi_{\text {Au-film }}$ и потенциала свободной поверхности арсенида галлия $\varphi_{\mathrm{GaAs}}$, что полностью согласуется с представлениями о термодинамической системе контакта М-П с БШ. В общем случае, как видно из рис. 6, II и 7, II, значение встроенного электростатического потенциала $\varphi_{\xi}^{*}$ легко может быть определено из выражения

$$
\varphi_{\zeta}^{*}=\varphi_{\mathrm{Au}-\text { film }}-\varphi_{\mathrm{Au}-\mathrm{Contact}}^{\xi} .
$$

Согласно полученным результатам, а также [8,9], влияние электростатического потенциала на статические BAX проявляется в понижении эффективной (измеренной) высоты обратно смещенного барьера Шоттки на величину $\varphi_{\xi}^{*}$ :

$$
\varphi_{b m, r, \text { Light }}^{\xi} \approx \varphi_{b m, f, \text { Dark }}^{\xi}-\varphi_{\xi}^{*} .
$$

Для контактов $L$-типа с большой площадью $\left(D_{L 1}\right)$ значение $\varphi_{\text {Au-Contact }}^{L, 1}$ близко к значению потенциала сплошной пленки золота $\varphi_{\text {Au-film. Значение встроенного по- }}$ тенциала $\varphi_{L, 1}^{*}$ при этом минимально, а значение $E_{L, 1}^{*}$ максимально, что, согласно (12), ведет к уменьшению электростатического поля периферии (рис. 6 и табл. 3). Хорошо видно, что уменьшение площади $S_{L}$ сопровождается значительным изменением значений поверхностного потенциала контактов $\varphi_{\text {Au-Contact, }}^{L}$ увеличением встроенного потенциала $\varphi_{L}^{*}$ и уменьшением модуля $E_{L}^{*}$, что, согласно (15), сопровождается увеличением $E_{l}^{\xi}$, усилением результирующего электростатического поля ОПЗ и в конечном итоге увеличением фотоэдс $U_{\mathrm{Ph}}^{L}$ (рис. 3 и табл. 3). Из табл. 3 видно, что модуль электростатического поля периферии $E_{l}^{\xi}$, определяемый параметром $\xi_{\xi}$, хорошо коррелирует с фотоэдс $U_{\mathrm{Ph}}^{\xi}$. Таким образом, можно сделать вывод, что параметр $\xi_{\xi}$ связан с величиной фото эдс $U_{\mathrm{Ph}}^{\xi}$ посредством электростатического поля периферии $E_{l}^{\xi}$.

Постоянство значений $\varphi_{\mathrm{Au}-\mathrm{Contact}}^{M} \approx$ const, $\varphi_{M}^{*} \approx$ const электростатической системы и значений фотоэдс $U_{\mathrm{Ph}}^{M}(18)$ для контактов $M$-типа $\left(\xi_{\xi}=\mathrm{const}\right)$ можно объяснить постоянными, не зависящими от формы контактов значениями модуля электростатического поля $E_{M}^{*}$ и, как следствие, электростатического поля периферии $E_{l}^{M}$ (рис. 7 и табл. 4). Действительно, для контактов $M$-типа изменение количества электрического заряда в ОПЗ $Q_{W}^{M}$ изменяется прямо пропорционально изменению площади боковой поверхности. Согласно теореме Остроградского-Гаусса, это обеспечивает постоянство плотности потока вектора смещения электрического поля $E_{M}^{*}$ через боковую поверхность ОПЗ контактов $M$-типа, что в результате и приводит к постоянству значений фотоэдс $U_{\mathrm{Ph}}^{M}=$ const.

В добавление к предложенным объяснениям следует отметить, что для МДП-контактов (металл-диэлектрик полупроводник - $\mathrm{Au}-\mathrm{SiO}_{2}-n$-GaAs) I-типа значения поверхностных потенциалов металлических контактов $\varphi_{\text {Au-Contact }}^{I}(\mathrm{MДП)}=$ const не зависят от диаметра контактов [16]. Согласно предложенной физической модели контакта, так происходит потому, что в МДП-структурах I-типа практически отсутствует ОПЗ и, как следствие, зависящая от $\xi_{I}$ составляющая $E_{I}^{*}=E^{*}\left(\xi_{I}\right)$, а $E_{\text {grad }}$, как известно, имеет постоянные, не зависящие от формы контактов значения [16].

Таким образом, именно наблюдаемая в экспериментах и зависящая от $\xi_{\xi}$ составляющая $E_{\xi}^{*}=E^{*}\left(\xi_{\xi}\right)$ электростатического поля периферии ответственна за наблюдаемые особенности фотогальванических эффектов 
и, согласно предложенной физической модели, может быть использована для существенного повышения эффективности преобразования световой энергии в электрическую в плоских выпрямляющих контактах металл-полупроводник с барьером Шоттки.

\section{5. Заключение}

Предложенная в работе физическая модель встроенных электростатических полей периферии может использоваться в качестве дополнения к физическим моделям плоских выпрямляющих контактов металл-полупроводник Шоттки-Мотта [26] или Бардина [27]. Из вышеизложенного следует, что наибольшее влияние встроенные электростатические поля периферии будут оказывать на электростатическую систему, вольт-амперные характеристики, токовую и вольтовую фоточувствительности выпрямляющих контактов М-П микронных и наноразмеров. Предложенная физическая модель основана на определяющей роли латеральной границы - периметра $P$ плоского контакта металл-полупроводник в формировании его аддитивных электрофизических, приборных и фотогальванических характеристик.

Физический механизм влияния периметра $P$ на электрофизические и приборные характеристики выпрямляющего плоского контакта М-П заключается в формировании за его периметром электростатического поля $E_{l}$, вектор которого образован суперпозицией векторов электростатических полей $E_{\text {grad }}$ и $E^{*}$. Вне периметра вектор $E_{l}$ направлен вдоль полупроводниковой поверхности от контакта в сторону убывания электростатического потенциала, а внутри периметра - сонаправлен с электростатическим полем ОПЗ $E_{W}$. Модуль вектора $E_{\text {grad }}$ постоянен, так как образован разностью поверхностных потенциалов барьерного контакта и полупроводниковой поверхности. Противоположно направленный ему вектор $E^{*}$ образован нескомпенсированным потоком вектора смещения электростатического поля ОПЗ $E_{W}$ через боковую поверхность ОПЗ [19]. Модуль электростатического поля $\left|E^{*}\right| \leq\left|E_{\text {grad }}\right|$ определяется плотностью потока вектора смещения электростатического поля $E_{W}$ через боковую поверхность ОПЗ и зависит не только от полного электрического заряда $Q_{W}$, но и от площади $S^{*}$ боковой поверхности ОПЗ. Таким образом, чем больше $Q_{W}(S)$ - контакты с большой площадью и меньше $P$, тем больше модуль $\left|E^{*}\right|$ и меньше модуль $\left|E_{l}\right|=\left|E_{\text {grad }}\right|-\left|E^{*}\right|$. Наблюдаемые эффекты в этом случае незначительны. И наоборот, чем меньше $Q_{W}(S)$ - контакты с маленькой площадью и больше $P$, тем меньше $\left|E^{*}\right|$ и больше модуль $\left|E_{l}\right|$, а наблюдаемые эффекты максимальны.

Влияние границы на электростатическую систему плоских выпрямляющих контактов $\mathrm{M}-П$ проявляется в уменьшении значений поверхностных электростатических потенциалов (работы выхода) металлических кон- тактов на величину $\varphi^{*}$, равную разности поверхностных потенциалов сплошной металлической пленки $\varphi_{M e-\text { film }}$ и металлического контакта $\varphi_{M e-\text { Contact, }}$ а также в образовании внутри и вокруг периметра контакта протяженного ореола - области изменения электростатического потенциала от электростатического потенциала поверхности металлического контакта до электростатического потенциала полупроводниковой поверхности.

На статических ВАХ контактов $\mathrm{M}-П$ малых размеров $(D<100$ мкм $)$ влияние электростатического поля периферии $E_{l}$ проявляется в сушественном превышении обратных токов насыщения над прямыми и образовании на начальном участке прямых ВАХ „мертвой“ области, характеризуемой отсутствием прямых токов. Наблюдаемые эффекты обусловлены значительным усилением электрического поля в периферийной области контакта посредством сложения сонаправленных электростатических полей $E_{l}$ и $E_{W}$.

Подобное усиление электростатического поля в периферийной области сопровождается значительным (на $\left.\varphi^{*}\right)$ понижением эффективной высоты барьера Шоттки для обратных $\mathrm{BAX}$, что и приводит к существенному увеличению обратных токов насыщения и повышению эффективности преобразования световой энергии в электрическую. Обнаруженная зависимость составляющей электростатического поля периферии $E^{*}$ от формы контакта является основой физических методов оптимизации по повышению эффективности преобразования световой энергии в электрическую в контактах металл-полупроводник с барьером Шоттки. Вызванная встроенным электростатическим полем периферии $E_{l}$ сильная (несколько порядков) зависимость значений относительных величин $\tilde{\beta}_{I}^{\xi}$ и $\tilde{\beta}_{U}^{\xi}$ от формы контактов говорит о том, что получение максимальных абсолютных значений токовой $\beta_{I}^{\xi}$ и вольтовой $\beta_{U}^{\xi}$ фоточувствительностей является нетривиальной задачей, требующей использования методов оптимизации, в основе которых лежат изложенные в данной работе положения физической модели плоских выпрямляющих контактов металл-полупроводник с учетом электростатических полей периферии. Было получено, что в общем случае значение фотоэдс $U_{\mathrm{Ph}}$ пропорционально отношению периметра контакта к его площади $\left(\xi_{\xi}=P_{\xi} / S_{\xi}\right)$, а сила фототока прямо пропорциональна протяженности периметра $P_{\xi}$. Тот факт, что сила фототока в исследуемых контактах М-П с БШ связана не с площадью, а с периметром контакта говорит о том, что с ограниченных площадей полупроводниковых чипов можно снимать достаточно большие электрические мощности.

Из-за того что для микронных и наноразмерных контактов Шоттки модуль электростатического поля периферии $\left|E_{l}\right|$ соизмерим с модулем ОПЗ $\left|E_{W}\right|$, его необходимо учитывать не только при физическом моделирования фотоэлектрических преобразователей (например, высокоэффективных солнечных элементов или высокочувствительных скоростных детекторов ионизи- 
рующего излучения), но и при физическом моделировании современных детекторных и преобразовательных диодов Шоттки миллиметрового и субмиллиметрового диапазонов длин электромагнитных волн [28,29].

В завершение изложенного можно добавить, что упоминающийся во Введении эффект „резонанса горячих электронов“, приводящий к аномальному увеличению внешней квантовой эффективности фотодиодов с барьером Шоттки, можно объяснить значительным усилением в них полевой эмиссии, вызванной встроенным электрическим полем периферии $E_{l}$.

Автор выражает благодарность коллективу Томского государственного университета систем управления и радиоэлектроники за помощь в проведении измерений электростатических характеристик диодов, а также коллективу Томского государственного университета за помощь в проведении измерений с использованием методов атомно-силовой микроскопии.

Работа выполнена при финансовой поддержке Министерства образования и науки РФ. Уникальный идентификатор 8.4029.2017/4.6.

\section{Список литературы}

[1] H. Hertz. Annalen der Physik, 267 (8), 983 (1887).

[2] Elster Julius, Geitel Hans. Annalen der Physik, 274 (12), 497 (1889).

[3] W. Schottky. Naturwissenschaften, 26, 843 (1938).

[4] H. Elabd, W. Kosonoky. RCA Rev., 43, 569 (1982).

[5] R.H. Fowler. Phys. Rev., 38, 45 (1931).

[6] V.L. Dalal. J. Appl. Phys., 42, 2227 (1971).

[7] V.E. Vichers. Appl. Optics, 10, 2190 (1971).

[8] Н.А. Торхов. ФТП, 44 (6), 767 (2010).

[9] Н.А. Торхов. ФТП, 45 (7) 965 (2011).

[10] В.Г. Божков, С.Е. Зайцев. Изв. вузов. Радиофизика, $\operatorname{XLVII}(9), 769$ (2004).

[11] H.O. Jacobs, P. Leuchtmann, O.J. Homan, A. Stemmer. J. Appl. Phys., 84 (3), 1168 (1998).

[12] В.Г. Божков, Н.А. Торхов, И.В. Ивонин, В.А. Новиков. ФТП, 42 (5), 546 (2008).

[13] А.В. Анкудинов, В.П. Евтихеев, К.С. Ладутенко, А.Н. Титков, R. Laiho. ФТП, 40 (8), 1009 (2006).

[14] В.Л. Миронов. Основы сканирующей зондовой микроскопии (Нижний Новгород, Институт физики микроструктур РАН, 2004).

[15] H.O. Jacobs, P. Leuchtmann, O.J. Homan, A. Stemmer. J. Appl. Phys., 84 (3), 1168 (1998).

[16] Н.А. Торхов, В.А. Новиков. ФТП, 45 (1), 70 (2011).

[17] Н.А. Торхов. ФТП, 44 (5), 615 (2010).

[18] Н.А. Торхов. Поверхность. Рентгеновские, синхротронные и нейтронные исследования, 1, 1 (2010).

[19] Н.А. Торхов. Изв. вузов. Физика. Депонировано в ВИНИТИ № 334-В2008 от 18.04.2008.

[20] Н.А. Торхов. ФТП, 45 (8), 1041 (2011).

[21] Л.И. Бабак, А.Ф. Купрейчик, В.А. Новиков, А.С. Сальников, Н.А. Торхов. Матер. III Междунар. заочной науч.практ. конф. „Наука вчера, сегодня, завтра“ (Новосибирск, „СибАК“, 2013) с. 36.
[22] Р.К. Мамедов. Контакты металл-полупроводник с электрическим полем пятен (Баку, БГУ, 2003).

[23] Н.А. Торхов, В.Г. Божков, И.В. Ивонин, В.А. Новиков. Поверхность. Рентгеновские, синхротронные и нейтронные исследования, 11, 1 (2009).

[24] Н.А. Торхов, В.А. Новиков, А.А. Мармалюк, Ю.Л. Рябоштан. Матер. 22-й Междунар. Крымской конф. „СВЧ-техника и телекоммуникационные технологии“ (Cевастополь, Крым, Украина, 2012) с. 633.

[25] Н.А. Торхов, В.Г. Божков, В.А. Новиков, И.В. Ивонин. Матер. 25-й Междунар. Крымской конф. „СВЧ-техника и телекоммуникационные технологии“ (Севастополь, Крым, Россия, 2015) с. 611.

[26] J. Bardeen. Phys. Rev., 71 (10), 717 (1947).

[27] E.H. Rhoderick, R.H. Williams. Metall-semiconductor contacts. 2nd edn (Clarendon, Oxford, 1988).

[28] Н.А. Торхов, Л.И. Бабак, А.А. Коколов. Матер. 26-й Междунар. Крымской конф. „СВЧ-техника и телекоммуникационные технологии“ (Севастополь, Крым, Россия, 2016) c. 275

[29] Н.А. Торхов. Заявка на полезную модель. 2016104746 от 11.02.2016.

Редактор Г.А. Оганесян

\section{The influence of periphery electrostatic field upon the photovoltaic effect in metal-semiconductor contacts with Schottky barrier}

\author{
N.A. Torkhov ${ }^{1,2,3}$ \\ ${ }^{1}$ Scientific-Research Institute of Semiconductors, \\ 634034 Tomsk, Russia \\ ${ }^{2}$ Tomsk State University of Control Systems \\ and Radioelectronics, \\ 634050 Tomsk, Russia \\ ${ }^{3}$ Tomsk State University, \\ 634050 Tomsk, Russia
}

\begin{abstract}
The investigation of electrostatic system of flat metal-semiconductor contacts with Schottky barrier reveals a non-trivial dependency of their current and voltaic photosensibility (photovoltaic effect) on the shape of contacts. The usage of the photovoltaic effect in such contacts depends largely on built-in electrostatic field of the periphery, which magnitude is defined by the contacts' perimeter and area. Therefore, to improve the efficiency of photo-to-electric energy conversion by Schottky contacts, it is necessary to use optimization techniques based on the presented in this work ideas on physical model of electrostatic system of flat Schottky contacts with due regard to the periphery electrostatic field. The „hot-electron resonance“ effect resulting in increasing external quantum efficiency of Schottky photodiodes can be explained by the field electron emission intensification induced by the periphery electrostatic field.
\end{abstract}

